\title{
08 FUNGAL MOLECULAR BIOLOGY
}

\author{
08.001 - THE HSP 70 GENE PRESENTS SEQUENCE DIFFERENCES AMONG \\ ISOLATES OF PARACOCCIDIOIDES BRASILIENSIS \\ Teixeira, M. M. ${ }^{1}$; De Carvalho, M. J. A. ${ }^{2}$; Dantas, A. S. ${ }^{3}$; Felipe, M. S. S. ${ }^{4}$ \\ ${ }^{1,4} \mathrm{UnB}$ - Departament of Cell Biology; ${ }^{2,3} \mathrm{UnB}$ - Departament of Cell Biology
}

Introduction and Objectives: Paracoccidioides brasiliensis is a thermodimorphic fungus and is the ethiologic agent of Paracoccidioidomicose. This dimorphic fungus undergoes a complex differentiation in vivo and is responsible for one of the most prevalent mycosis in Latin America. During in vitro growth, phase transitions are triggered when the incubation temperature is shifted from $26^{\circ} \mathrm{C}$ to $37^{\circ} \mathrm{C}$ or in the reverse direction. When exposed to environmental stress such as temperature elevation, all living organisms respond by rapidly producing increasing amounts of heat shock proteins (Hsps), which presumably protect cells against the effects of the stress agent. Although a number of heat shock proteins have been identified, Hsp70 is one of the most abundant. Because our group is interested in studying genes involved in the transition from mycelium to yeast, we decided to analyze sequences of the hsp70 gene in different isolates of P. brasiliensis. Methods and Results: We amplified and sequenced the $h s p 70$ genomic sequences of 21 isolates. We also aligned the $h s p 70$ sequences of the 21 isolates, using the program Clustal W, to verify differences or similarities between them. We found the following additional sequences within the hsp70 gene of isolate $\mathrm{Pb} 01$ in comparison to the homologs in other isolates: three regions with 16, 23 and 22 base pairs located in the first intron of this gene. We also confirmed that the third region $(22 \mathrm{bp})$ correspond to a microsatellite (CT) region. To verify the uniqueness of these sequences in the isolate $\mathrm{Pb} 01$, we designed a reverse primer based in the specific region $(23 \mathrm{bp})$ located in the first intron and a forward primer based in the 5' UTR region common to all isolates of $P$. brasiliensis used in this analysis. A fragment of $400 \mathrm{bp}$ was amplified by PCR only in the $\mathrm{Pb} 01$ isolate. Conclusion: We found intrinsic differences in the hsp70 gene of $P$. brasiliensis which may account for heterogeneity between isolates and also it was used as a specific region for the isolate Pb01 Financial support: MCT, CNPq AND FAP-DF

\subsection{2 - TRANSPOSABLE ELEMENTS IN THE EXPRESSED SEQUENCE TAGS (ESTS) OF PARACOCCIDIOIDES BRASILIENSIS: CHARACTERIZATION OF TWO MAJOR RETROTRANSPOSONS IN THE FUNGUS PARTIAL TRANSCRIPTOME.}

Araujo, R. A. C. ${ }^{1}$; Guerra, A. C. P. ${ }^{2}$; Moreira, E. S. A. ${ }^{3}$; Santos, M. R. M. ${ }^{4}$; Gentil, L. G. ${ }^{5}$; Soares, C. M. A. ${ }^{6}$; Brigido, M. ${ }^{7}$; Felipe, M. S. S. ${ }^{8}$; Franco da Silveira, J. ${ }^{9}$; Cisalpino, P. S. ${ }^{10}$ ${ }^{1,2,3,10}$ UFMG - Microbiologia; ${ }^{4,5,9}$ UNIFESP - Microbiologia, Imunologia e Parasitologia; ${ }^{6}$ UFG Department of Biochemistry and Molecular Biology; ${ }^{7,8} \mathrm{UnB}$ - Departament of Cell Biology

Introduction and Objectives:Transposable elements (TEs) were cited among the most abundant ESTs in P.brasiliensis partial transcriptome. TEs are genetic units with ability to integrate into the genome at a new site within their cell of origin. They include RNA mediated retrotransposons and DNA transposons. By their mobility these agents are mutagenic and produce structural changes in single genes and overall genomes followed by altered patterns of gene expression. We present data on a survey of TEs in the P. brasiliensis assembled ESTs database (PbAESTs) (J.Biol.Chem.280:24706-24715, 2005) and the characterization of two major retrotransposons in the transcriptome. Methods and Results: TEs survey was carried out on PbAESTs by computational search using key words related to mobile genetic elements. 393 clones (1,5\% of the ESTs), organized in 51 contigs and 84 singlets, fulfilled the specifications: 23 contigs had significant similarity to known retrotransposons and 4 seemed DNA transposons. Two contigs, contig 400 (97 reads, 50\% of the retroelement related sequences) and contig 1609 (18 reads), represented distinct putative retroelements, and were named PbRtp1 and PbRtp2. The PbRtp1 deduced ORFs had domains highly similar to reverse transcriptases, integrases and chromatin-organization modifiers (chromodomain), compatible with LTR (Long Terminal Repeat) retrotranposons. The ORF of PbRtp2, probably a nonLTR retrotranposon, had a conserved ribonuclease $\mathrm{H}$-like domain. $P$. brasiliensis isolates $\mathrm{Pb}$ 01, Pb18 and PbB339 were employed for DNA and RNA extraction, and the preparation of chromosomal sized-DNA. Purified inserts from each element were labeled and used as probes for the hybridization of Southern blots, Northern blots and Chromoblots. The hybridization patterns of Southern blots of the genomic DNA from each isolate, digested with different endonucleases, were very similar and showed the existence of multiple copies of each element in the fungus genome. Probes PbRtp1 and PbRtp2 mapped to all the chromosomal-sized DNA bands from isolate $\mathrm{Pb} 18$, however, $\mathrm{PbRtp} 2$ probes did not assign the $7,7 \mathrm{Mb}$ band from isolate PbB-339. PbRtp1 transcripts were detect by hybridization of Northern blots of the total RNA from the yeast phase of isolate PbB339. Conclusion: Twenty three contigs of the PbAESTs showed significant similarity to TEs. Two major putative retrotransposons, PbRtp1 and PbRtp2, respectively a LTR and a non-LTR retrotransposon, were identified. Their genomic organization and transcriptional patterns were preliminarly characterized. Mobile elements are becoming useful tools for learning more about genome evolution and gene function. Characterization of TEs will contribute to a better knowledge of the structure of $P$. brasiliensis genome and to a better understanding their functional roles. Financial support: CNPq; FAPESP(JFS).

\author{
08.003 - MOLECULAR CHARACTERIZATION OF PARACOCCIDIOIDES \\ BRASILIENSIS CLINICAL AND ENVIRONMENTAL ISOLATES BY RAPD, RFLP \\ AND PFGE. \\ Guerra, A. C. P. ${ }^{1}$; Araujo, R. A. C. ${ }^{2}$; Carneiro, R. A. ${ }^{3}$; Moreira, E. S. A. ${ }^{4}$ Cisalpino, P. S. ${ }^{5}$ \\ 1,2,3,4,5,5 UFMG - Microbiologia
}

Introduction and Objectives: Considerable genotypic variation was reported when $P$. brasiliensis isolates were typed by random amplification of polymorphic DNA in the polymerase chain reaction (RAPD-PCR), allowing sometimes the establishment of correlations between genetic patterns and epidemiological data. Restriction fragment length polymorphism (RFLP) analysis was scarcely used although referred as able to reveal the existence of correlations between RFLP patterns and geographic origins of the isolates. Pulsed field gel electrophoresis (PFGE) revealed chromosomal polymorphism and intraspecific genetic variation, however, no possible correlation with epidemiological data was indicated. Virtually no previous work employed multiple methods for genotyping the same set of $P$ brasiliensis isolates. We present data on the molecular characterization of 24 P. brasiliensis clinical and environmental isolates, from different geographic regions, by RAPD, RFLP and PFGE. Methods and Results: Total DNA was extracted and samples were analysed by RAPD using six primers: OPG03, OPG16, OPG18, OPG11, OPG15, OPO06. Each primer showed fingerprinting patterns that can distinguish at least two genotypic groups: two groups were distinguished with primer OPG11, 3 with OPG18, 4 groups with OPG03, OPG15 and OPG16, and 5 groups with OPO06. DNA from 8 isolates were digested with endonucleases HinfI and $B g l I I$, and hybridized with probes corresponding to two major retrotransposons (sequences of median repetitiveness in the genome of eukaryotes, potentially usefull as markers in molecular epidemiology) from $P$. brasiliensis transcriptome, PbRtp1 e PbRtp2. The fragment length polymorphism generated with Hinfl showed banding patterns that will be usefull by itself. After hybridization of probes the presence of multiple copies of each element was shown and the profiles generated by BglII were particularly polymorphic, allowing the differentiation of isolates. Karyotyping confirmed the previously stated polymorphism of number (4-5) and sizes of chromosomal bands, and at least 5 clearly distinct chromosome banding profiles could be seen among 18 isolates solved by PFGE. The analysis are going to be extended to the whole set of isolates. Dendrograms will be generated by computational analysis employing individual and global results on RAPD, RFLP (patterns from each endonuclease and after the hybridization with each probe), and PFGE. Conclusions. The results will probably permit to verify the existence of correlations between genotypic patterns generated by three different methods, the existence of correlations between particular genotypes and the epidemiological information available on each isolate, and the applicability of the results on the estimation of the genetic distance among the isolates, contributing to a better knowledge about aspects of the biology of the microorganism related to genetic variation and recombination. Financial support: $\mathrm{CNPq}$

08.004 - THE CATALASE A OF PARACOCCIDIOIDES BRASILIENSIS: PROTEOMIC IDENTIFICATION, CDNA CLONING AND CHARACTERIZATION Chagas, R. F. ; Bailao, A. M. ${ }^{2}$; Pereira, M. ${ }^{3}$; Felipe, M. S. S..$^{4}$ C Castro, N. S. ${ }^{5}$; Soares, C. M. A. 1,2,3,5,6UFG - Department of Biochemistry and Molecular Biology ; ${ }^{4} \mathrm{UnB}$ - Departament of Cell Biology

Introduction and Objectives: The pathogenic fungus Paracoccidioides brasiliensis is the ethiological agent of Paracoccidioidomycosis (PCM) the most prevalent systemic mycosis in Latin America. The fungus grows as mycelium at $22^{\circ} \mathrm{C}$, and as yeast at $36^{\circ} \mathrm{C}$ in vitro and in the host tissues. Pathogens are exposed to the reactive oxygen species (ROS) derived from endogenous and exogenous sources. Those organisms possess a number of antioxidan enzymes that serve as protective mechanisms. Those enzymes include superoxide dismutase (SOD), glutathione peroxidase (GPX), peroxiredoxin and catalase. Catalases are antioxidant metalloenzymes, which protect cells against oxidative damage caused by hydrogen peroxide produced by phagocytes cells of the host. There are three families of catalases: Mn catalases, bifunctional catalases and monofunctional catalases. The last family corresponds to homotetrameric heme-containing enzymes that are composed of two clearly distinct classes, large-subunit and small-subunit catalases. In the present work we characterized the cDNA encoding a catalase A of $P$. brasiliensis and identified it in the fungus proteome. In addition we compared the transcriptional expression of $\mathrm{Pb}$ CatA in the different phases of the pathogen, yeast and mycelia, as well as evaluated the expression of catalase A in the presence of $\mathrm{H} 2 \mathrm{O} 2$. Methods and Results: A cDNA encoding a catalase A of $P$. brasiliensis ( $\mathrm{Pb}$ CatA) was characterized (GenBanK accession number AY494834). The complete cDNA presents 2583 nucleotides and the deduced protein presents 760 amino acids. It could be observed the active site and the presence heme-ligand signature of catalases besides also amino acids residues related to the binding to the substrate and to the correct folding of catalases had been identified. Homology search and phylogenetic analysis indicated that $P b$ CatA is highly similar to other catalases of large-subunits of pathogenic fungi. A protein species of $84 \mathrm{kDa}$, pI 6.12 was isolated from two-dimensional gels and submitted to microsequencing of interna peptides. The native protein revealed strong homology to catalase A from several sources and corresponds to the obtained cDNA ( $\mathrm{Pb}$ CatA). The expression of transcripts encoding $\mathrm{Pb}$ CatA was assessed by Northern blot hybridizations of total RNA. These results 


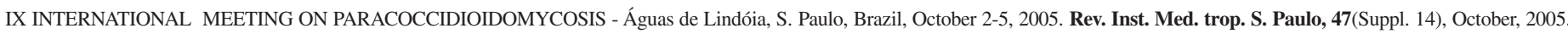

demonstrated that the RNA is more abundant in mycelia than in yeast phase of $P$. brasiliensis. Western blotting analysis showed that the expression of the catalase A was increased when the fungus was treated with $\mathrm{H} 2 \mathrm{O} 2$. Conclusion: The obtained cDNA encode a putative catalase of $84 \mathrm{kDa}$ of $P$. brasiliensis. The deduced amino acid sequence is similar to the others largesequence-subunit catalases of fungi. The mRNA was more abundant in the mycelial infective phase. The protein was induced in the presence of the substrate suggesting a putative role in the protection against ROS in the life cycle of the pathogen. Financial support: MCT/CNPq and FUNAPE/UFG.

\subsection{5 - PARACOCCIDIOIDES BRASILIENSIS CELL WALL: SOME GENES} INVOLVED IN SYNTHESIS AND REMODELING

Nino-Vega, G. ${ }^{1}$; Sorais, F. ${ }^{2}$; Barreto, L. ${ }^{3}$; Moreno, B. ${ }^{4}$; Paulinkevicius-Novoa, M. ${ }^{5}$; San-Blas, $\mathrm{G}^{6}$

1,2,3,4,5,6 Instituto Venezolano de Investigaciones Científicas (IVIC) - Laboratorio de Micologia

Introduction: In P. brasiliensis cell wall, the yeastlike (Y) phase, but not the mycelial (M) one, contains $\alpha-1,3$-glucan as the main $(95 \%)$ glucose polymer (Mycopathologia 62 : $77-86,1977)$. It is synthesized by $\alpha-1,3$-glucan synthase (PbrAGS) and hydrolysed by $\alpha$ 1,3-glucanase (PbrAGase), an autoregulatory system of synthesis and degradation. Their genes shape $P$. brasiliensis, together with others like the chitin synthase (CHS) family of genes, of which PbrCHS5 probably directs the deposition of actin. Herein we present results on their sequencing and expression. Methods: Growth of P. brasiliensis Pb73 (ATCC 32071) and molecular techniques were as before (Yeast 21: 211-218, 2004). In some experiments, medium was supplemented with 5\% horse serum (HS). To study the PbrAGase gene, heterologous Southern and colony hibridization were done using a Histoplasma capsulatum $750 \mathrm{bp}$ fragment as radiolabeled probe. To analyse the upstream region of PbrCHS5 (Med. Mycol., 38: 31-39, 2000), amplification was done by the PCR-step down technique (Gene 253: 145-150, 2000). Introns were confirmed by RT-PCR or the 3 RACE system (Invitrogen, CA). Results: Northern analysis of PbrAGS indicated that its expression was limited to the $Y$ phase, in agreement with biochemical data. Subculturing in vitro of $P$. brasiliensis $\mathrm{Pb} 73$ led to thinner $\alpha$-glucan layer and loss of the multibudding round shape of $Y$ cells. Addition of $5 \%$ HS increased the $\alpha$-glucan layer from $30 \%$ to more than $50 \%$ of the wall, and restored the round multibudding shape. There was no increment in PbAGS1 expression. The deduced $\mathrm{PbrAGase}$ protein is truncated at the N-terminal region, showing homology to fungal alpha glucanases for the fragment obtained. Expression of the gene was confirmed on both $\mathrm{Y}$ and $\mathrm{M}$ phases by RT-PCR. Procedures for the upstream region analysis of CHS5 generated a $3084 \mathrm{bp}$ product. Its ORF had $5849 \mathrm{nt}$, interrupted by three introns of 82,87 and $97 \mathrm{bp}$; the polyadenylation signal was located 585 nucleotides downstream the termination codon. Its deduced protein was homologous to the equivalent fungal proteins. It presents a putative myosin motor-like domain. Conclusions: A post-transcriptional regulation of PbrAGS1 may be occurring, as reported for Schizosaccharomyces pombe (Mol. Biol. Cell. 11: 4393-4401, 2000). Although expression of PbAGase has been confirmed by RT-PCR, quantitative measurements by northern have not yet been possible. Currently, we are searching a genomic library to look for the 5' region of PbAGase. The PCR-step down technique allowed the completion of the 5' end of PbrCHS5, a task unsuccessful with other methods. Acknowledgement: FONACIT (grant G97-000615), Venezuela.

\subsection{6 - ANTIZYME AS REGULATOR OF ORNITHINE DECARBOXYLASE (ODC) IN PARACOCCIDIOIDES BRASILIENSIS}

Cordero, M. ${ }^{1}$; Nino-Vega, G. ${ }^{2}$; San-Blas, G. ${ }^{3}$

${ }^{I}$ Instituto Venezolano de Investigaciones Científicas (IVIC) - Laboratorio de Micologia: ${ }^{2,3}$ Instituto Venezolano de Investigaciones Científicas - Centro de Microbiología y Biología Celular

Introduction: In P. brasiliensis, growth of the pathogenic yeastlike (Y) phase and transition from the mycelial (M) to the $\mathrm{Y}$ phase are accompanied by an increase in polyamines levels and ODC activity (Arch. Microbiol. 165: 311-316, 1996; ibid 166: 411-413, 1997). Northern analysis of the PbrODC gene does not correlate with such increment in activity, showing a constant expression during $\mathrm{Y}$ growth and through transition either way, pointing to a post-translational regulation of ODC (Yeast 21: 211-218, 2004). In some fungi and in mammalian cells, a feedback system post-translationally regulates antizyme activity (Rev. Iberoamer. Micol. 20:1-5, 2003). In it, low levels of ODC (and polyamines) give place to an inactive antizyme by a frameshifting of its transcript. When the levels of ODC (and polyamines) rise, the antizyme transcript is made in frame, giving as a result an active antizyme protein that leads to the degradation of ODC protein. When the levels of ODC (and polyamines) decrease, the antizyme transcript suffers a frame shift, thereby inactivating the antizyme and restarting the cycle, through a self-regulatory mechanism. Methods: Southern analysis on $P$. brasiliensis DNA was done using as radiolabeled probe a PCR fragment of $330 \mathrm{bp}$ of the P. brasiliensis antizyme gene (PbrAzODC). From the Southern analysis, a HindIIII genomic library was constructed, that was screened by colony hybridization, in order to get the whole gene sequence. The polyadenylation site has been identified by the $3^{\prime}$ RACE system (Invitrogen, CA), using as specific primers, sequences derived from the PCR product. Expression of the gene was followed by Northern analyses in the $\mathrm{Y}$ and $\mathrm{M}$ phases, as well as during the dimorphic switch from M to Y. As loading control, a fragment of the PbrrRNA 18S gene was used. Results: From Southern analysis, a single $2.9 \mathrm{~Kb}$ signal was detected for DNA restricted with HindIII, and this enzyme was chosen for the construction of a genomic library. Northern analysis showed a higher expression of $\mathrm{PbrAzODC}$ in the $\mathrm{Y}$ pathogenic phase when compared with the $\mathrm{M}$ phase, and a rise in signal intensity for samples into the dimorphic transition from $\mathrm{M}$ to $\mathrm{Y}$. Conclusions: Both the higher expression of the PbrAzODC gene in the pathogenic $\mathrm{Y}$ phase than in the saprophytic $\mathrm{M}$ phase, and the rise in expression when an $\mathrm{M}$ culture changes into a $\mathrm{Y}$ culture, correlates with the higher ODC activity found when $P$. brasiliensis presents the $\mathrm{Y}$ morphology. The presence of an antizymelike protein together with the above results, allow us to postulate that, like in some fungi and in mammalian cells, regulation of ODC in P. brasiliensis might be antizyme-controlled.

\subsection{7 - PBRSEP2, A MEMBER OF THE PARACOCCIDIOIDES BRASILIENSIS SEPTIN FAMILY \\ Rodríguez-Brito, S. ${ }^{1}$; Nino-Vega, G. ${ }^{2}$; San-Blas, G. ${ }^{3}$}

${ }^{1,2,3}$ Instituto Venezolano de Investigaciones Científicas (IVIC) - Laboratorio de Micologia

Introduction: Septins are proteins involved in a wide variety of processes from cytokinesis and cell morphology, to regulation of the cell cycle in eukaryotic cells. In fungi, they are involved in selection of the budding place, chitin deposition, and spore cell wall formation. In this work we set up to study PbrSEP2, one of the genes conforming this family in Paracoccidioides brasiliensis, and its expression when the thermal transition from the mycelial (M) to the yeastlike (Y) phase occurs. Methods: Southern analysis on P. brasiliensis DNA was done using as radiolabeled probe a PCR fragment of $660 \mathrm{bp}$, amplified with degenerated primers, designed on high homology regions for fungal septins. From Southern analysis, a $P s t \mathrm{I}$ genomic library was costructed, which is being screened by colony hybridization, in order to get the whole gene sequence. The polyadenylation site has been identified by the 3 'RACE system (Invitrogen, CA) using the sequence of the PCR product for the design of specific primers. Expression of the gene was followed by Northern analyses in the $\mathrm{Y}$ and $\mathrm{M}$ phases, as well as during the dimorphic switch from $\mathrm{M}$ to $\mathrm{Y}$. As loading control, a fragment of the PbrrRNA 18S gene was used. Results: The deduced aminoacid sequence for the PCR product obtained by the use of degenerated primers, shows high identity to Emericella nidulans asp-C and other fungal septin proteins, and has been designated PbrSEP2. An 840 bp fragment was amplified by the 3' RACE system. Sequencing of the amplified fragment confirmed the ending point of the gene and its 3'UTR region up to the polyadenylation site. Northern analyses show gene expresion in $\mathrm{Y}$ and $\mathrm{M}$ cells, although an incresing signal was detected when transition occurred from the $\mathrm{M}$ to the $\mathrm{Y}$ phase, with higher expression at $72 \mathrm{~h}$ into the transition. Conclusions: Expression of the PbrSEP2 gene increases during the $\mathrm{M}$ to $\mathrm{Y}$ transition, with a higher expression $72 \mathrm{~h}$ into the transition, when more than $90 \%$ of the culture shows yeastlike structures. This result might suggest the importance of this gene in the formation of the spherical morphology. Reverse genetics studies could help to clarify this preliminary finding and the role of the PbrSEP2 gene in morphogenetics.

\subsection{8 - PARACOCCIDIOIDES BRASILIENSIS GENOME SIZE AND PLOIDY}

Almeida, A. J. ${ }^{1}$; Martins, M. ${ }^{2}$; Carmona, J. A. ${ }^{3}$; Torres, I. ${ }^{4}$; McEwen, J. G. ${ }^{5}$; Restrepo, A. ${ }^{6}$; Leao, C. ${ }^{7}$; Rodrigues, F. ${ }^{8}$

1,2,3,7,8 University of Minho, Braga, Portugal - Life and Health Sciences Research Institute, School of Health Sciences $;{ }^{4,5}$ Corporación para Investigaciones Biológicas, Medellin, Colombia - Cellular and Immunogenetics Group; ${ }^{6}$ Corporación para Investigaciones Biológicas, Medellin, Colombia - Medical and Experimental Mycology Group

Introduction and Objectives: Although recent molecular approaches have allowed an important approximation to the genomic size and ploidy of the dimorphic pathogenic fungus Paracoccidioides brasiliensis, definitive conclusions are far from having being achieved. In this sense, the primary objective of this study was to assess the genome content and ploidy of several $P$. brasiliensis strains accordingly with its multinucleate nature.Methods and Results: During the course of this work, a flow cytometry (FCM) technique previously developed in our laboratory to study the cell cycle profile of $P$. brasiliensis yeast cells was applied (unpublished data). Discriminated cell subpopulations with different DNA content were individually analyzed after cell sorting, revealing distinct cell morphology and nuclei content. In accordance with the FCM analysis of uninucleated cells, we estimated the DNA content of nine $P$. brasiliensis strains, both clinical and environmental. The DNA content of all strains ranged from $29.9 \pm 0.2$ to $34.8 \pm 0.5 \mathrm{Mb}$ per uninucleated cell. Furthermore, the ploidy level of several strains was assessed by conjugating these data with its previously determined electrophoretic karyotype (Fungal Genet Biol. 21(2):223-7, 1997; Med Mycol. 37(3):219$22,1999)$. All the studied strains were shown to have a haploid, or at least aneuploid, DNA content. Conclusion: This study provides information that addresses fundamental questions of $P$. brasiliensis biology, such as genome size and ploidy. Our findings are also an important contribution to the development of molecular techniques, such as gene disruption and/or overexpression, for the future genetic manipulation of this human pathogen. Furthermore, and even though natural ploidy levels of several strains have been determined during this study, its relevance in P. brasiliensis pathogenicity and/or pathogenesis still remains an enigma. Financial support: Almeida, A. J. was supported by a fellowship from Fundação para a Ciência e Tecnologia (FCT), Portugal (contract SFRH/BD/8655/2002). This work was supported by a research grant from FCT (Grant Number: POCTI/ESP/45327/2002). 
08.009 - THE RECEPTOR FOR ACTIVATED C KINASE 1 HOMOLOGUE OF PARACOCCIDIOIDES BRASILIENSIS: STRUCTURAL AND PHYLOGENETIC ANALYSIS

Castro, N. S. ${ }^{1}$; Maia, Z. A. ${ }^{2}$; Felipe, M. S. S. ${ }^{3}$; Castro, K. P. ${ }^{4}$; Pereira, M. ${ }^{5}$; Soares, C. M. A. ${ }^{6}$ ${ }_{1,2,4,5,6}$ UFG - Department of Biochemistry and Molecular Biology; ${ }^{3}$ UnB - Departament of Cell Biology

Introduction and Objectives: Paracoccidioides brasiliensis is a temperature dependent dimorphic fungus, the etiological agent of Paracoccidioidomycosis (PCM). Morphogenic transition plays a role in the fungus pathogenesis. Inhaled conidia differentiate into yeast cells in the human lungs, establishing the infection. Little is known about the signaling pathways that control the morphological changes in P. brasiliensis. Here, we focus on one cDNA Pbrack1 (GenBank: AF548359), encoding a homologue of RACK1, which has a highly conserved WD domain with homology to the b subunit of heterotrimeric G proteins. RACK1 functions on mammalian signal transduction pathways most notably as an adaptor protein for the bII protein kinase C isozyme. The interactions of RACK1 with a critical regulator of cAMP metabolism suggest that the protein may be intimately involved in the regulation of pathways activated by adenylyl cyclase. In single-cell eucaryotes, RACK1/ $\mathrm{cpc} 2$ also regulates growth, differentiation and entry into Go stationary phase. Methods and Results: Analyses of the deduced $P b R A C K 1$ by bioinformatics programs revealed seven repeats of the WD40 motif, a characteristic of this family of proteins. This motif is described as involved in protein-protein interactions. P $b$ RACK1 presents conserved PKC binding sites in the WD40 repeats III and VI. The protein is $94 \%$ and $91 \%$ identical to the Aspergillus nidulans and Neurospora crassa RACKs respectively. Phylogenetic analyses among RACK1 homologs were performed and $P b$ RACK1 is found in a sub clade restricted to fungi. The mRNA was present in higher levels in the mycelia saprobic phase than in the subsequent yeast phase. The rack1 gene is present as a single copy in the genome of P. brasiliensis as suggested by Southern blot analysis. RACK1 was expressed in bacteria as a fusion protein with GST using the pGEX-4T-3 vector. The expression of the recombinant protein in Escherichia coli BL21 Star (DE) containing the plasmid was induced and the recombinant protein purification is under progress. Conclusion: Since at least some of the proteins that bind to RACKs including PKC itself regulated cell growth and differentiation the studies involving RACKs could help to elucidate the signaling pathways leading to those processes in the dimorphic pathogenic fungus $P$. brasiliensis. Financial support: MCT/CNPq, CAPES, FUNAPE-UFG

08.010 - A FAMILY OF BETA (1-3) GLUCANOSYLTRANSFERASES OF PARACOCCIDIOIDES BRASILIENSIS: IDENTIFICATION, COMPARATIVE ANALYSIS AND HETEROLOGOUS EXPRESSION

Castro, N. S. ${ }^{1}$; Castro, K. P. ${ }^{2}$; Maia, Z. A. ${ }^{3}$; Felipe, M. S. S. ${ }^{4}$ Pereira, M. ${ }^{5}$; Nino-Vega, G. ${ }^{6}$; Soares, C. M. A.

${ }_{1,2,3,5,7}$ UFG - Department of Biochemistry and Molecular Biology; ${ }^{4}$ UnB - Departament of Cell Biology; ${ }^{6}$ Instituto Venezolano de Investigaciones Científicas - Centro de Microbiología y Biología Celular

Introduction and Objectives: Paracoccidioidomycosis is a human systemic mycosis caused by the thermal dimorphic fungus Paracoccidioides brasiliensis. The fungus molecular architecture and functional components of the cell wall vary between yeast and mycelial forms. The role of the cell wall constituents $\alpha$-1,3-glucan and $\beta$-1,3-glucan in the regulation of the dimorphic transition in $P$. brasiliensis has been subject of many studies and recent reviews. The $\alpha$-glucanosyltransferases are periplasmic and cell wall-associated enzymes, responsible for the elongation of beta-1,3-glucan chains. They are representatives of cell wall-bound proteins with GPI linkages and function in the remodeling of newly synthesized polysaccharide polymers of the fungal cell wall. Methods and Results: Here, we describe two cDNAs Pbgel2 and Pbgel3 encoding beta-1,3-glucanosyltransferases. A BLAST search analysis revealed that the cDNA Pbgel3 (GenBank: AY324033) and Pbgel2 (GenBank: AY340235) present homologues in fungi. Alignments of the predicted $P$. brasiliensis protein sequences showed that the PbGEL2 is $34 \%$ identical and $67 \%$ similar to the PbGEL3. The deduced amino acid sequences of both cDNAs contain a conserved glutamate residue in two conserved catalytic motifs of this family of glycosyl hydrolases, family 72. Cysteine residues, which are conserved in the primary structure of the reported fungal glucanosyltransferases, and a hydrophobic $\mathrm{C}$ terminus with a predicted GPI anchor site, were found at $P b$ GEL3 3 and $P b$ GEL2. A third glucanosyltransferase sequence encoding Pbgel1 cDNA was obtained by PCR from a cDNA library of $P$. brasiliensis. Partial results reveal a putative signal peptide and GPI anchor sites which characterize the glucanosyltransferases and GPI-anchored proteins in $P b$ GEL1. In order to start functional studies of those molecules, the Pbgel 3 cDNA was introduced into pTWIN1 vector to produce the recombinant protein and into pYES2 vector to functional complementation in Saccharomyces cerevisiae. Both experiments are under progress. Conclusion: The GPI-anchored proteins of microbial pathogens have been shown to be immunogenic and represent virulence factors. In addition to those aspects its localization at the cell surface and theirs active role in cell wall biosynthesis makes the glucanosyltransferases interesting targets for the design of new drugs against PCM. Financial support: $\mathrm{MCT} / \mathrm{CNPq}$, CAPES, FUNAPE-UFG
08.011 - THE MITOCHONDRIAL GENOME FROM THE THERMAL DIMORPHIC FUNGUS PARACOCCIDIOIDES BRASILIENSIS

Cardoso, M. A. G. ${ }^{1}$; Tambor, J. H. M. ${ }^{2}$; Nobrega, F. G. ${ }^{3}$

${ }^{1,3}$ Universidade do Vale do Paraíba - Instituto de Pesquisa e Desenvolvimento; ${ }^{2}$ Universidade de São Paulo - Instituto de Química

Introduction and Objectives: Paracoccidioides brasiliensis is a thermo dimorphic fungus that causes a deep systemic infection in humans (PCM), and undergoes a complex transformation: mycelia grows at room temperature and the pathogenic yeasts form at $36^{\circ} \mathrm{C}$ Mitochondrial physiology is clearly affected in the mycelial to yeast transformation ( $\mathrm{J}$ Bacteriology, 169:4055-4060, 1987). To deepen our understanding of mitochondrial functions in this organism we have sequenced the entire mitochondrial DNA (mtDNA) from Paracoccidioides brasiliensis, isolate 18. Methods and Results: Based on 1713 reads edited and aligned using Phred/Phrap/Consed and CAP3 programs, we could find the genes coding for the three subunits of the ATP synthase (ATP6, ATP8 and ATP9), apocytochrome b (COB), three subunits of the cytochrome c oxidase (COX1, COX2 and COX3), seven subunits of the NAD dehydrogenase (NAD1, NAD2, NAD3, NAD4, NAD5, NAD6 and NAD4L), the large (L-rRNA) and small (S-rRNA) subunits of the ribossomal RNA, two intronic maturases and a ribossomal protein (RMS-5). Twenty-five transfer RNAs were identified for all 20 aminoacids. Conclusion: The circular genome comprises $71,335 \mathrm{bp}$ and is characterized by an $\mathrm{A}+\mathrm{T}$ content of $75 \%$. The intergenic regions are composed of long $\mathrm{A}+\mathrm{T}$ stretches sometimes interrupted by polypirimidine repeats ranging from 140 to $240 \mathrm{bp}$ in length. The order of genes/proteins identified appear closest to the mitochondrial genome from Aspergillus nidulans although the size of both genomes are quite different, which is due mostly to the presence of abundant extragenic DNA in P. brasiliensis and also additional introns in COX1, COB, NAD5 and S-rRNA. Another, recently published, thermo-dimorphic fungus Penicillium marneffei has also great synteny with $P$. brasiliensis mtDNA, with the tRNA clusters having almost the same order in both genomes. Financial support: FAPESP and CNPq

\subsection{2 - CARACTERIZATION AND HETEROLOGOUS EXPRESSION OF A RECOMBINANT DFG5-LIKE PROTEIN OF PARACOCCIDIOIDES} BRASILIENSIS

Maia, Z. A. ${ }^{1}$; Castro, N. S. ${ }^{2}$; Castro, K. P. ${ }^{3}$; Felipe, M. S. S. ${ }^{4}$; Pereira, M. ${ }^{5}$; Soares, C. M. A. ${ }^{6}$ $1,2,3,5,6$ UFG - Department of Biochemistry and Molecular Biology; ${ }^{4}$ UnB - Departament of Cell Biology

Introduction and Objectives: Paracoccidioides brasiliensis is a dimorphic pathogenic fungus, the causal agent of paracoccidioidomycosis, a systemic disease which predominantly affects rural communities in South and Central America. The dimorphic transition in $P$. brasiliensis is readily induced in vitro by temperature changes, resulting in modulation of the composition of cell wall. Here, our studies focus on a DFG5-like protein, a predicted plasma membrane molecule which has been shown to be involved in cell wall biogenesis and to be essential for cell growth in organisms such as Saccharomyces cerevisiae and Candida albicans. Methods and Results: We originally identified from a cDNA library of $P$. brasiliensis by using the probe $P b$ Ymnt (GenBank: AF374353) encoding a mannosyltransferase, the dfg5 cDNA of P. brasiliensis (GenBank: AY307855). Sequence analyses revealed that $P b \mathrm{dfg} 5$ encodes a protein with a domain characteristic of the glycosy hydrolase family 76 and also presents homology to bacterial mannosidases. The translated amino acid sequence of the PbDFG5 predicted a protein of 448 amino acid residues, with a molecular mass of $49.9 \mathrm{kDa}$ and $\mathrm{p} I$ of 5.7. A potential cleavage site characteristic of the GPIanchored proteins was found at $\operatorname{Ser}^{220}$. The cell attachment sequence, RGD (arginine-glycineaspartic acid), was predicted by protein sequence analysis using the PROSITE algorithm. Moreover, sequence analysis of the P. brasiliensis deduced DFG5, revealed that 22 amino acids at the N-terminus have the characteristic of a signal peptide. The cDNA encoding DFG5 was cloned into the SalI/NotI sites of pGEX-4T-3 to yield the dfg5-pGEX-4T-3 construct. The recombinant plasmid was used to transform Escherichia coli competent cells and the rDFG5 protein was induced with $0,4 \mathrm{mM}$ of IPTG. The production of antibodies against the recombinant DFG5 is under progress. Functional studies will be performed. Conclusions: Our data suggest that PbDFG5 can be a probable GPI-anchored membrane protein involved in cell wall biosynthesis and putatively required for cellular differentiation and growth, as described to other microorganisms. In this way, the study of the PbDFG5 may be an interesting goal for elucidating the molecular mechanisms of differentiation of $P$. brasiliensis and for the design of new drugs against PCM. Financial support: MCT/CNPq, CAPES, FUNAPE-UFG 
08.013 - A PROLINE-RICH ANTIGEN (PRA/AG2) HOMOLOGUE OF PARACOCCIDIOIDES BRASILIENSIS

Castro, K. P. ; Castro, N. S. ${ }^{2}$; Maia, Z. A. ${ }^{3}$; Felipe, M. S. S. ${ }^{4}$; Pereira, M. ${ }^{5}$; Soares, C. M. A. ${ }^{6}$ ${ }_{1,2,3,5,6}$ UFG - Department of Biochemistry and Molecular Biology; ${ }^{4}$ UnB - Departament of Cell Biology

Introduction and Objective: The thermal dimorphic fungus Paracoccidioides brasiliensis causes paracoccidioidomycosis (PCM), the leading endemic deep mycosis in Latin America The disease may develop as different forms, ranging from benig and localized to severe and disseminated forms. Fungal conidia $\left(20-23^{\circ} \mathrm{C}\right)$ start the infection by converting to the yeast parasitic phase in human lungs $\left(37^{\circ} \mathrm{C}\right)$. The morphological switch from mycelia to yeast is the most important biological feature that enables $P$. brasiliensis to colonize, invade and survive in host tissues during infection. PRA/Ag2 protein has been reported to be a surface antigen in fungi. PRA/Ag2 is a component of a glycopeptide, which is probably the main T-cell-reactive component of Coccidioides immitis cell walls, for example. Also, the recombinant PRA/Ag2 protein is reactive with sera from patients with active coccidioidomycosis. This protein is suggested to have an endoglucanase activity and to be important for spherule cell-wal morphogenesis during the infection process by $C$. immitis. It is located in the fungal cell wall, most probably attached to the cell wall matrix. Due to those characteristics we searched for the cDNA encoding the homologue of PRA in P. brasiliensis. Methods and Results: Here, we describe a cDNA Pbpra encoding a proline-rich antigen homologue of $P$. brasiliensis. The identified ORF codes for a putative polypeptide of 184 amino acids with a predicted molecular mass of $18.4 \mathrm{kDa}$ and $p I$ of 7.55 . Analysis by bioinformatics programs suggested that PRA/ $\mathrm{Ag} 2$ contains a signal peptide with cleavage site between $\mathrm{Ala}^{18}$ and $\mathrm{Gln}^{19}$ and is probably located in cell wall. The deduced amino acid sequence also showed a region that contains 7 repeats of the tetrapeptide TXX'P, where X is Ala, His, or Glu and X' is Ala, Val, or Glu. A search for protein patterns at the PROSITE Database revealed probable phosphorylation sites (Casein Kinase II and protein Kinase C), N-myristoylation sites and one predicted CFEM domain $\left(\mathrm{Gln}^{19}-\mathrm{Ser}^{84}\right)$. CFEM is a fungal specific cysteine-rich domain which is found in some proteins with proposed roles in fungal pathogenesis. A putative signal peptide and GPI anchor sites $\left(\mathrm{Gly}^{161}\right)$ which characterize the GPI-anchored proteins were found in PbPRA. The expression construct pra-pGEX-4T-3 was introduced into Escherichia coli to produce a recombinant protein. Functional studies will be performed. Conclusions: GPI-anchored protein of various microbial pathogens have been shown to be highly immunogenic and are required for morphogenesis, virulence and for host-fungus interactions. These reasons can be invoked to account for the importance of GPI-anchored proteins in P. brasiliensis. Financial support: $\mathrm{MCT} / \mathrm{CNPq}$, CAPES, FUNAPE-UFG

\subsection{4 - REPRESENTATIONAL DIFFERENCE ANALYSIS (RDA) IN THE IDENTIFICATION OF GENES EXPRESSED BY A PARACOCCIDIOIDES BRASILIENSIS ISOLATE WHICH DOES NOT PRESENT DIMORPHISM IN RESPONSE TO TEMPERATURE UPSHIFT}

Borges, C. L. ${ }^{1}$; Bailao, A. M. ${ }^{2}$; Santos, M. O. ${ }^{3}$; Fiuza, R. B. ${ }^{4}$; Felipe, M. S. S. ${ }^{5}$; Bao, S. N. ${ }^{6}$; Martins, W. S. ${ }^{7}$; Pereira, M. ${ }^{8}$; Soares, C. M. A. ${ }^{9}$

${ }_{1,2,3,8,9}$ UFG - Biochemistry and Molecular Biology; ${ }^{4}$ Universidade Católica de Goiás - Departament of Computer Science; ${ }^{5}$ UnB - Departament of Cell Biology; ${ }^{6}$ UnB - Department of Cell Biology; ${ }^{7}$ Universidade Católica de Goiás - Department of Computer Science

Introduction and Objectives: Paracoccidioidomycosis (PCM) is a systemic mycosis caused by the thermal dimorphic fungus Paracoccidioides brasiliensis, the leading endemic deep mycosis in Latin America. The fungus grows in the yeast phase at $36^{\circ} \mathrm{C}$, and as mycelium at $22{ }^{\circ} \mathrm{C}$. The dimorphic transition from the mycelial to the yeast form is induced by a shift from environmental temperature to the temperature of the mammalian host. Little information is available on the $P$. brasiliensis genes that are necessary for the dimorphic transition and in the establishment of infection. Specific features of the fungus that may play a critical role in infection include cell wall composition and its ability to grow at $36{ }^{\circ} \mathrm{C}$. We performed sets of subtraction hybridization (RDA) with cDNA populations obtained from two isolates, which present different morphologies at $36{ }^{\circ} \mathrm{C}$. Our objective is the identification of genes that could be related to the transition in response to the temperature upshift. Methods and Results: Pb01 (ATCC MYA-826) and Pb4940 (collected from liquor of a patient) isolates, were cultivated for 7 days at $36^{\circ} \mathrm{C}$. Electron microscopy were performed with the two P. brasiliensis isolates, showing, at $37^{\circ} \mathrm{C}$, yeast phase for $\mathrm{Pb} 01$, and mycelial phase for $\mathrm{Pb} 4940$ isolate. PCR using random primers was employed to characterize the $P b 4940$ and the typical isolate $P b 01$. RAPD patterns allowed the clustering of those isolates into different groups. Total RNA was extracted from both isolates and cDNA libraries were constructed. Both isolates were used as testers and drivers for obtaining differentially expressed products, in two rounds of subtraction. Subtracted products were cloned into pGEM-T-Easy (Promega, Madison, USA) and plasmids were transformed into Escherichia coli competent cells. Positive colonies were picked and grown in microliter plates. Plasmid DNA was prepared from clones and the DNA was sequenced with the MegaBACE 1000 DNA sequencer (Amersham Biosciences) by standard fluorescence labeling dye-terminator protocols with the T7 primer vector. A pipeline was built to analyze and assemble the ESTs, using the programs Phred, Crossmatch and CAP3. The clones were sequenced and assembled in contigs and singletons, showing a high redundancy in the identified genes. The resulted contigs and singletons were analyzed. We identified genes related to cell wall metabolism, stress response, virulence, which could be related to the temperature induced transition. Conclusion: The RDA was able to identify differentially expressed genes between two isolates grown in the same conditions. Some identified genes such as ClpA and an alternative oxidase have been described as virulence factors. Over expressed genes could be potentially involved in the cell wall metabolism and heat shock stress, reinforcing the role of those molecules in the temperature induced phase transition. Financial support: $\mathrm{MCT} / \mathrm{CNPq}$

\subsection{5 - CHARACTERIZATION OF AN ASPARTYL PROTEINASE OF} PARACOCCIDIOIDES BRASILIENSIS

Tacco, B. A. C. A. ${ }^{1}$; Costa, M. ${ }^{2}$; Parente, J. A. ${ }^{3}$; Felipe, M. S. S. ${ }^{4}$; Castro, N. S. ${ }^{5}$; Pereira, M. ${ }^{6}$; Soares, C. M. A. ${ }^{\text {? }}$

1,2,3,3,6,7 UFG - Department of Biochemistry and Molecular Biology; ${ }^{4}$ UnB - Departament of Cell Biology

Introduction and Objectives: Paracoccidioides brasiliensis is the ethiological agent of Paracoccidioidomycosis the most prevalent systemic mycosis in Latin America. This dimorphic fungus undergoes a complex differentiation in vivo. The mycelia produce conidia, which upon inhalation into the lungs transform to the yeast form. One factor that contributes to the process of virulence seems to be the production of proteolytic enzymes. Aspartyl proteinases of fungi are secreted primarily to provide nutrients for the cell and to fulfill a number of specialized functions during the infective process. The protein allows microorganisms to evade the host defenses by degrading immunoglobulins and complement proteins and also by promoting adherence and degradation of host barriers during invasion. Aspartyl proteinases are synthesized as zymogens that are self-actived by proteolytic removal of a peptide segment under acidic conditions, first in the endoplasmic reticulum and then in the vacuole to generate the active, mature form of the protein. In this work we present the characterization of a $1.3 \mathrm{~Kb}$ cDNA $(\mathrm{PbAP})$, encoding a protein homologous to related sequences of aspartyl proteinases of several organisms. Comparative analysis of the deduced protein was performed. Methods and Results: Recently we identified in P. brasiliensis a complete cDNA (GenBank-AY278218) encoding an aspartyl proteinase homologous to related sequences from several microorganisms. The cDNA and the deduced protein were characterized by searchs in databases. The deduced $P b A P$ presents a molecular mass of 43.8 $\mathrm{kDa}$ and $p I$ of 5.7. Conserved amino acids at the putative active site, a characteristic signal peptide and a putative signal peptide were present. An amplified $1200 \mathrm{bp}$ PCR product was inserted into pGEMT Easy (Promega), in the XhoI and EcoRI sites, and the recombinant plasmid was introduced into E.coli cells. Also, the aspartyl proteinase gene was cloned by PCR of genomic DNA of $P$. brasiliensis. The mRNA expression profile was studied by Northen Blot analysis. Conclusion: The characterization of the cDNA of the aspartyl proteinase from $P$. brasiliensis opens the possibility of analyzing the role of the protein as virulence factor in this fungus. The cloning and characterization of the cDNA, and its future heterologous expression, will provide the tools for understanding the physiological role of this protein in P. brasiliensis pathogenesis. Financial support: MCT/CNPq, CAPES and FUNAPE-UFG

\subsection{6 - THE 14-3-3 PROTEINS OF PARACOCCIDIOIDES BRASILIENSIS: COMPARATIVE ANALYSIS OF TWO CDNAS ENCODING PB14-3-3 1 AND PB14- 3-3 2}

Tacco, B. A. C. A. ${ }^{1}$; Cunha-Passos, D. A. ${ }^{2}$; Felipe, M. S. S. ${ }^{3}$; Castro, N. S. ${ }^{4}$; Pereira, M. ${ }^{5}$; Soares, C. M. A. ${ }^{6}$

${ }^{1,2,4,5,6}$ UFG - Department of Biochemistry and Molecular Biology ; ${ }^{3}$ UnB - Departament of Cell Biology

Introduction and Objectives: Paracoccidioidomycosis (PCM) is a deep mycosis of high incidence in Latin America. Its ethiological agent is Paracoccidioides brasiliensis, a thermally dimorphic fungus which alternates between an unicellular yeast form $\left(37^{\circ} \mathrm{C}\right)$ and filamentous mycelia $\left(26^{\circ} \mathrm{C}\right)$. The 14-3-3 proteins are a large family of acidic proteins with a high degree of sequence identity and conservation. A wide array of biological functions for the 14-3-3 protein family has been described, like involvement in cell cycle progression, in cytoeskeletal organization, in signal transduction, in stress response, in apoptosis, in cell differentiation, among others. This wide array of cellular functions attributed to the 14-3-3 proteins specially in cellular differentiation, the latter one the main event for the establishment of infection by $P$. brasiliensis, has led our group to initiate studies with Pb14-3-3s. Methods and Results: Two full-length cDNAs were isolated and characterized encoding the 14-3-3 protein homologues of P. brasiliensis, 14-3-3.1 and 14-3-3.2. Pb14-3-3.2 is $64.5 \%$ identical to $P b 14-3-3.1$. The deduced amino acid sequences of $P b 14-3-3.1$ and $P b 14-3-3.2$ present three regions, as following: a divergent amino acidic terminus, a conserved core region and a divergent carboxy terminus. Homology search analysis and preliminary molecular modeling indicate that both $\mathrm{Pb} 14-3-3 \mathrm{~s}$ may present 9 alpha helices, that could be organized in an antiparallel manner, suggesting an L-shaped structure, as described for the 14-3-3 family. The helices H3 and H5, which contain many charged and polar amino acids and $\mathrm{H} 7$ and $\mathrm{H} 9$, which contain hydrophobic amino acids, could compose the L-shaped structure. Southern blot analysis suggests that both $P b 14-3-31$ and $P b 14-3-32$ genes are present in only one copy in the P.brasiliensis genome. Studies concerning to the $P b 14-3-3.1$ and $P b 14-3-3.2$ expression in P. brasiliensis are under progress. Conclusion: The characterization of 14-3-3 proteins can provide additional data for the understanding of the intracellular signaling pathways in $P$. brasiliensis, the mechanisms by which the microorganism may interact with the environment and with the host's immunological system, by triggering responses to diverse stimulus. The presence of 14-3-3 proteins in most, if not all, eukaryotic cells, but not in any prokaryotic cells, offers an interesting opportunity to study this protein family and its regulatory processes in P. brasiliensis. Financial support: $\mathrm{MCT} / \mathrm{CNPq}$, CAPES and FUNAPE-UFG 
08.017 - IN VIVO-INDUCED ANTIGEN TECHNOLOGY (IVIAT) ALLOWS THE IDENTIFICATION OF IMMUNOGENS OF PARACOCCIDIOIDES BRASILIENSIS Moreira, S. F. I. ${ }^{1}$; Rezende, T. C. V. ${ }^{2}$; Costa, M. ${ }^{3}$; Felipe, M. S. S. ${ }^{4}$; Oliveira, E. H. D. ${ }^{5}$; Bailao, E. F. L. C. ${ }^{6}$; Pereira, M. ${ }^{7}$; Hahn, R. C. ${ }^{8}$; Soares, C. M. A.

${ }_{1,2,3,5,6,7,9} \mathrm{UFG}$ - Department of Biochemistry and Molecular Biology ; ${ }^{4} \mathrm{UnB}$ - Departament of Cell Biology; ${ }^{8}$ Universidade Federal de Mato Grosso - Hospital Universitário Julio Muller

Introduction and objectives: Paracoccidioides brasiliensis is the etiological agent of the paracoccidioidomycosis (PCM) a fungal disease prevalent in Latin America. The fungus occurs as mycelium at $26^{\circ} \mathrm{C}$ and as yeast at $36^{\circ} \mathrm{C}$. In vivo induced antigen technology (IVIAT) is a technique that identifies antigens expressed in vivo during human infection. IVIAT has been used for the identification of open reading frames (ORFs) that may play a role in virulence or pathogenesis. The objective of this work is to identify immunogenic proteins of $P$. brasiliensis expressed specifically during human infection, which might help the pathogen to adapt to the hostile in vivo environment. This technology is expected to facilitate the discovery of new targets for vaccines, for drugs and to provide diagnostic strategies. Methods and Results: The strain $P b 01$ was used to infect male mice and their infected livers were cultivated for 7 days. The fungal RNA was extracted and used to construct a cDNA expression library. Sera were collected from five patients with PCM from Cuiabá (MT). Equal volumes of sera were pooled and adsorbed against whole yeast cells, yeast cell lysates and heatdenatured yeast cell lysates of the in vitro grown $P b 01$. This adsorbed serum has been used to screen the cDNA expression library cloned into pCMV-SPORT1. We identified 28 positive clones in a first screening, which encode proteins related to cell membrane (1-2galactosyltransferase), to cellular transport (ABC-type nitrate/sulfonate/bicarbonate, ABC sugar transport systems and high affinity cooper transporter), to the respiratory chain (NADH dehydrogenase, mitochondrial citocromo b and c), to cell metabolism (aldehyde dehydrogenase, monooxygenase, zinc binding dehydrogenase, DOPA decarboxylase, oxidoreductase and Acyl - CoA dehydrogenases), to regulatory proteins (zinc finger and ubiquitin), to cellular signaling proteins (protein tyrosine phophatases, histidine protein kinase and Rack-1), to putative virulence factors (cofilin and Rho GTPases) and to 9 hypotetical proteins. Conclusions: The clones identified using the IVIAT presents limited information from the literature and databases with respect to the precise role of these genes in pathogenesis. It was clear, however, that those genes were putatively involved in a variety of functions, such as cellular metabolism, pathogenesis and adaptation of $P$. brasiliensis to the host. The genes characterized in this study will be further investigated in relation to their relevance in human infection. Financial support: CAPES, FUNAPE/GO, MCT/CNPq.

\subsection{8 - TRANSCRIPTOME PROFILE OF YEAST CELLS FROM} PARACOCCIDIOIDES BRASILIENSIS WITHIN MURINE MACROPHAGES

Tavares, A. H. ${ }^{1}$; Silva, S. S. ${ }^{2}$; Silva Pereira, I. ${ }^{3}$; Fachin, A. L. ${ }^{4}$; Passos, G. A. S. ${ }^{5}$; Andrade, R. V. ${ }^{6}$; Felipe, M. S. S.

${ }^{1,2,3,6,7}$ UnB - Departament of Cell Biology; ${ }^{4,5}$ USP - Departament of Genetic

Introduction and Objectives: $P$. brasiliensis act as a facultative intracellular pathogen is able to survive and replicate within the phagosome of nonactivated murine and human macrophages. This ability, as proposed for Histoplasma capsulatum and Mycobacterium tuberculosis, is crucial to the development of disease. Thus, P. brasiliensis may have evolved mechanisms that counteract the constraints imposed by phagocytic cells. By using cDNA microarray we evaluate the transcriptional response of this fungus to the environment of peritoneal murine macrophages in order to shed light on the mechanisms used by P. brasiliensis to survive within those phagocytic cells. Methods and Results: ex vivo peritoneal murine macrophages were infected with $P$. brasiliensis yeast. At different time points after infection a differential lysis procedure released intracellular fungi that were collected by centrifugation and its total RNA isolated using TRIZOL reagent. Two sets of microarrays containing a total of 1,152 clones from a P. brasiliensis cDNA library (J Biol Chem 280: 24706-24714, 2005) in the form of PCR products were spotted on Hybond N nylon membranes. After quantification of the amount of DNA deposited in each spot, membranes were used for hybridization against \pm -33P-labeled cDNA complex probes derived from reverse transcribed total RNA of intracellular yeast or in vitro grown yeast (control). Image acquisition of membranes was made by phosphor imager followed by data normalization and analysis using Bzscan and SAM softwares. Our results show that at 6 hours post infection 40 genes are significantly up regulated and 173 down regulated when comparing intracellular versus in vitro grown yeast cells. Among those up regulated genes we were able to find genes that may be directly involved in the ability of $P$. brasiliensis to survive within macrophages such as $60 \mathrm{kDa}$ heat shock protein (Hsp60) and cytosolic $\mathrm{Cu} / \mathrm{Zn}$ superoxide dismutase (CuSOD). Conclusion: for the first time a global gene expression tool is used for the expression analysis of $P$ brasiliensis genes when inside host cells. Our preliminary data analyses suggest a transcriptional plasticity of $P$. brasiliensis in response to the harsh environment of macrophages which may lead to adaptation and consequent survival of this pathogen. Financial support: MCT, FAP-DF, CNPQ, CAPES.

\subsection{9 - IDENTIFICATION OF NEW ANTIGENS OF PARACOCCIDIOIDES BRASILIENSIS BY USING THE IVIAT TECHNOLOGY}

Rezende, T. C. V. ${ }^{1}$; Castro, N. S. ${ }^{2}$; Moreira, S. F. I. ${ }^{3}$; Santos, M. O. ${ }^{4}$; Felipe, M. S. S. ${ }^{5}$; Oliveira, E. H. D. ${ }^{6}$; Pereira, M. ${ }^{7}$; Soares, C. M. A. ${ }^{8}$

Department of Biochemistry and Molecular Biology; ${ }^{5} \mathrm{UnB}$ - Departament of Cell Biology

Introduction and Objectives: Paracoccidioides brasiliensis is a thermally dimorphic fungus causing paracoccidioidomycosis (PCM), a mycosis that affects 10 million individuals in Latin America. The infection is acquired by inhaling airborne propagules produced by the fungal mycelium form which transforms into the pathogenic yeast form, when at the body temperature. The yeast form can either be eliminated by the cells of the immune system or dissemine to other tissues through lymphatic or hematogenous routes, occasioning several lesions, until death. $P$ brasiliensis expresses in-vivo many important virulence genes that may contribute to the overall fungus pathogenicity. We utilized in vivo-induced antigen technology (IVIAT) to identify new $P$. brasiliensis antigens that could be expressed during the infection process. IVIAT is a modified immunoscreening that circumvents the need for animal models and permits identification of antigens expressed at various stages of infection. Methods and Results: We used the IVIAT strategy to identify $P$. brasiliensis genes putatively induced in vivo. Using this technique we selected immunogenic proteins which should be expressed specifically during human infection and not during growth under standard laboratory conditions. Sera from eleven patients with PCM infection obtained in Goiânia were pooled and after that were adsorbed with whole cells and lysates of the in vitro cultured yeast phase. These sera were probed to induced proteins from a cDNA expression library of the yeast phase of $P$. brasiliensis constructed in IZAPII. Clones were obtained and characterized. Of special note is a cDNA ( $P b l s)$ encoding a 174 amino acid residues protein characterized as 6,7-dimethyl-8-ribityllumazine synthase ( $P b \mathrm{LS}$ ) homologue $P$. brasiliensis (GenBank: DQ081183). This protein catalyzes the penultimate step in the synthesis of riboflavin in plants, fungi, and microorganisms. In order to produce antibodies against the recombinant $P b \mathrm{LS}$ the expression construct pGEX-4T-3-LS was introduced into Escherichic coli cells and the expression and purification of the recombinant protein was obtained. The immunological activity of the recombinant protein will be investigated. Conclusion: Some studies reported that 6,7-dimethyl-8-ribityllumazine synthase represent attractive targets for the development of drugs against pathogens, since the inhibitors of those enzymes are not likely to interfere with enzymes of the mammalian metabolism. Other studies showed that DNA vaccines using recombinant 6,7-dimethyl-8-ribityllumazine synthase is a strong immunogen and elicits both humoral and cellular immune responses confering protection in mice. Those data make very interesting the study of this protein in $P$. brasiliensis. Financia support: $\mathrm{MCT} / \mathrm{CNPq}$ and FUNAPE

\subsection{0 - C-24 STEROL METHYLTRANSFERASE (ERG6) OF} PARACOCCIDIOIDES BRASILIENSIS

Santos-Silva, L. K. ${ }^{1}$; Rodrigues Silva, C. ${ }^{2}$; Cruz, A. H. S. ${ }^{3}$; Soares, C. M. A. ${ }^{4}$; Pereira, M. ${ }^{5}$ ${ }_{1,2,3,5}$ UF - Department of Biochemistry and Molecular Biology; ${ }^{4} U F G$-Department of Biochemistry and Molecular Biology

Introduction and Objectives: Paracoccidioides brasiliensis, a thermodimorphic fungus, is the causative agent of paracoccidioidomycosis the most prevalent mycosis in Latin America. The disease is acquired when propagules of the mycelial phase (in laboratory this form is maintained at $22^{\circ} \mathrm{C}$ ) are inhaled. The infection is thought to take place firstly in the lungs and then may disseminate via the bloodstream and/or lymphatic routes to others organs and tissues. Currently available antimycotics are frequently toxic at therapeutic dosages and it has been described $P$. brasiliensis isolates resistant to antifungals, mainly in imunodepressed patients. Some of the current antifungals affect sterols of fungi in targets that are common to humans causing side effects to patients. Ergosterol is the sterol of the yeast plasma membrane, which affects its fluidity, permeability and the activity of membrane-bound enzymes. This sterol differs from cholesterol, the predominant mammalian sterol, by the presence of a 24 methyl group and $\mathrm{D}^{7}$ and $\mathrm{D}^{22}$ double bonds. The c- 24 sterol methyltransferase (ERG6) is the enzyme that adds the 24-methyl group to ergosterol being absent in humans. Thus, ERG6 is considered to be a target to rational drug design avoiding possible side effects. In this work our aim is the cloning and sequencing of the ERG6 cDNA. Methods and Results: Oligonucleotides were constructed based on a partial cDNA sequence encoding to ERG6 detected in transcriptome of $P$. brasiliensis (http://www.biomol.unb.br). PCR was performed by using the mycelium cDNA libraryand the fragment of 500bp amplified was used as probe to screen the cDNA library of $P$. brasiliensis. One of the clones was chosen for sequencing. The sequence was analyzed by using computational programs such as Gene Runner and BLAST, suggesting being an ERG6 cDNA. The predicted protein from cDNA presents high homology with ERG6 from fungi. Southern blot was carried out to verify the number of copies of ERG6 in P. brasiliensis genome, indicating a single copy. Conclusion: The results suggest the presence of a single copy of ERG6 in P. brasiliensis. The partial ERG6 cDNA sequence presents similarities with ERG6 of others fungi. Based on the results, new sequencing will be carried out to get the complete cDNA sequence. Financial support: IFS, CNPq, CAPES and FUNAPE/UFG 
08.021 - CDNA REPRESENTATIONAL DIFFERENCE ANALYSIS USED IN THE IDENTIFICATION OF GENES EXPRESSED BY PARACOCCIDIOIDES BRASILIENSIS DURING THE INFECTIVE PROCESS

Bailao, A. M. ${ }^{1}$; Dutra, V. ${ }^{2}$; Borges, C. L. ${ }^{3}$; Parente, J. A. ${ }^{4}$; Fiuza, R. B. ${ }^{5}$; Felipe, M. S. S. ${ }^{6}$ Martins, W. S. ${ }^{7}$; Almeida Jr, N. F. ${ }^{8}$; Pereira, M. ${ }^{9}$; Schrank, A. ${ }^{10}$; Soares, C. M. A. ${ }^{11}$

${ }^{1}$ UFG - Department of Biochemistry and Molecular Biology; ${ }^{2}$ Universidade Federal do Mato Grosso - Department of Veterinary Medical Clinic; ${ }^{3,4,9,11}$ UFG - Department of Biochemistry and Molecular Biology; ${ }^{5,7}$ Universidade Católica de Goiás - Department of Computing; ${ }^{6}$ UnB Department of Cell Biology; ${ }^{8}$ Universidade Federal do Mato Grosso do Sul - Department of Computing and Statistics; ${ }^{10}$ Universidade Federal do Rio Grande do Sul - Center of Biotechnology

Introduction and Objectives: Paracoccidioides brasiliensis is the ethiological agent of paracoccidioidomycosis, one of the most prevalent human systemic mycoses in Latin America. The pathogen is a dimorphic fungus that undergoes a complex differentiation in vivo. After entrance of acquired airborne microconidia into the mammalian host, the fungus differentiates into the parasitic yeast form. Through lymphatic and hematogenous dissemination routes $P$. brasiliensis can reach important organs such as liver and spleen. The understanding of the complex interactions between parasites and their host must include the identification of genes expressed during infection. Although already investigated the complete repertoire of genes associated with the infective process in $P$. brasiliensis remain largely unknown. Methods and Results: We have utilized an efficient approach for the identification of differentially expressed genes, which involves rapid sets of subtraction hybridization (RDA) of cDNAs prepared from two cell populations. The RDA analysis has not been previously related to pathogenic fungi. In the present study, the strategy was applied to $P$. brasiliensis obtained from infected animals and to the fungus treated with plasma and blood which mimics the haematogenic events of the fungus dissemination. Sequence determination of 1484 clones and comparative analysis at public databases and also at the $P$. brasiliensis functional genome database (http://www.biomol.unb.br/Pb) by using BLASTX algorithm, allowed the identification of 256 clusters with known orthologues. Additionally, unknown genes have also been identified in P. brasiliensis, which has not been described in previous transcriptome analysis. Differentially expressed genes include those, which are involved in the heat stress response, protein synthesis, lipid degradation, signal transduction, osmolarity response and some putative virulence factors. Some differentially expressed genes were confirmed by Northern and dot blot. Further RT-PCR experiments showed that the expression of some of those genes was also present in vivo during P. brasiliensis intravenous mouse infection. Conclusions: The application of RDA allowed the identification of genes up-regulated during the $P$. brasiliensis infective process, as well as during human plasma and blood treatments Some identified genes, such as GAPDH, serine proteinase and iron transporters have been described as virulence factors. Some new transcripts, not previously described in the $P$. brasiliensis in vitro transcriptome were present in at least one tested condition that mimics the human infection. Those findings suggest the usefulness of the cDNA-RDA strategy in identifying genes related to selected conditions and to the identification of new genes of this organism. Moreover the data provide an initial insight of the possible mechanisms by which P. brasiliensis ensure survival in the hostile environment of the blood and in the host tissues. Financial support: $\mathrm{MCT} / \mathrm{CNPq}$

08.022 - THE ISOCITRATE LYASE OF THE PARACOCCIDIOIDES BRASILIENSIS Cruz, A. H. S. ${ }^{1}$; Santos-Silva, L. K. ${ }^{2}$; Soares, C. M. A. ${ }^{3}$; Pereira, M.

${ }_{1,2,4}$ UFG - Departamento de Bioquímica e Biofísica; ${ }^{3} U F G$ - Department of Biochemistry and Molecular Biology

Introduction and Objectives: One of the most prevalent fungi in Latin America is Paracoccidioides brasiliensis, a dimorphic organism that grows either as mycelium at $22^{\circ} \mathrm{C}$ or yeast at $36^{\circ} \mathrm{C}$. This pathogen apparently has its natural habitat in soil or in plants from areas where paracoccidioidomycosis (PCM) is endemic. Rural workers become infected by inhaling dust containing the infecting propagules, which reach the pulmonary alveolar epithelium, where they differentiate to the yeast pathogenic form, and can be phagocyted by macrophages. Fungi and many other prokaryotic and eukaryotic microorganisms can utilize ethanol, acetate or fatty acids as the sole carbon source. The glyoxylate cycle is required for the utilization of these carbon sources. The key enzymes of the glyoxylate cycle are isocitrate lyase (ICL) and malate synthase (MLS). The ICL cleaves isocitrate to glyoxylate and succinate; MLS condenses glyoxylate with acetyl-CoA forming malate. It has been shown that genes of the glyoxylate cycle are induced when Saccharomyces cerevisae and Candida albicans are phagocytized by macrophages and $C$. albicans mutants lacking ICL gene are markedly less virulent than the wild type. Analyses of transcriptome from $P$. brasiliensis showed the presence of ICL and the Northern blotting analysis has shown that this gene is up-regulated in yeast. Since the glyoxylate cycle is absent in mammals, the enzymes MLS and ICL have been studied as target for antifungal drugs. In this way our aim is cloning, sequencing, structural, phylogenetic and expression analysis of the isocitrate lyase cDNA of the $P$. brasiliensis. Methods and Results: Based on a cDNA partial sequence from the database of the $P$. brasiliensis transcriptome (http://www.biomol.unb.br) two oligonucleotides were constructed. Yeast cDNA library PCR was performed and the fragment was used as probe. Southern blot was performed and the results showed that ICL is single copy in the $P$ brasiliensis genome. In order to obtain complete ICL cDNA, the screening of a yeast cDNA library of $P$. brasiliensis was performed. The clone obtained was sequenced and the cDNA and the predicted protein were characterized by using computational programs. Phylogenetic analysis shows the high homology among ICLs from fungi. Conclusion: Here we are reporting the complete cDNA encoding the ICL from $P$. brasiliensis. Southern blot analysis indicates that the ICL gene is a single copy. Financial support: IFS, CNPq, CAPES and FUNAPE/UFG

\subsection{3 - MALATE SYNTHASE OF THE FUNGUS PARACOCCIDIOIDES BRASILIENSIS: CLONING, CHARACTERIZATION AND EXPRESSION ANALYSIS IN DIFFERENT CARBON SOURCES}

Zambuzzi, P. F. ${ }^{1}$; Bonfim, S. M. R. C. ${ }^{2}$; Cruz, A. H. S. ${ }^{3}$; Soares, C. M. A. ${ }^{4}$; Pereira, M.

${ }^{1,3}$ UFG - Departamento de Bioquímica e Biofísica; ${ }^{2,5}$ Universidade Federal de Goiás - Departamento de Bioquímica e Biofísica; ${ }^{4} U F G$ - Department of Biochemistry and Molecular Biology

Introduction and Objectives: Paracoccidioidomycosis, the major human systemic mycosis in Latin America, is caused by the dimorphic fungus Paracoccidioides brasiliensis, developing in the mycelial form at $22^{\circ} \mathrm{C}$ and yeast at $36^{\circ} \mathrm{C}$. The infection is acquired by inhalation of airborne propagules produced by the fungal mycelium, which changes into pathogenic yeast-like cells at the host temperature and can be phagocyted by macrophages. Inside macrophages the Glyoxylate Cycle, unique pathway for glucose synthesis from lipids, can be activated by fungus. Isocitrate lyase and Malate synthase (MLS) are the key enzymes in this pathway for the production of energy. The enzyme MLS catalyzes the conversion of glyoxylate to malate. It is thought that inhibitors of the MLS will be powerful antifungals without side effects in the patients, once this enzyme is absent in humans. The availability of the $P$. brasiliensis transcriptome makes possible to get the molecules present in fungus but absent in human as new targets for the antifungals drugs. A MLS EST was identified in the transcriptome of $P$. brasiliensis (http://www.biomol. unb.br). The objective of this work is the cloning of the complete MLS cDNA, as well as, the characterization of the predicted protein and the transcript expression analysis in different carbon sources. Methods and Results: Yeast and mycelium cells of $P$. brasiliensis, isolate $P b 01$ (ATCC MYA 826), were grown in Saboraud Dextrose medium at $36^{\circ} \mathrm{C}$ and $22^{\circ} \mathrm{C}$, respectively. Southern blotting was carried out to determine the number of copies of MLS in P. brasiliensis. The presence of two MLS genes named MLS1 and MLS2 was confirmed. The clones of the MLS1 and MLS2 were gotten by screening of the yeast cDNA library. The clones were sequenced and the analysis of the predicted protein showed that MLS1 has a complete cDNA but MLS2 has a partial cDNA. The high homology among MLS1, MLS2 and others MLSs from databases was observed. The expression of the MLS1 has been evaluated in different carbon sources (glucose, acetate, glycolate) by using RT-PCR. Initial results showed that MLS1 is expressed in the presence glucose. Conclusion: The Southern blotting analysis suggests the presence of two MLS genes in P. brasiliensis. Structural analysis of the MLS1shows the presence of the signature to MLS. Results obtained by RT-PCR suggest that MLS1 was expressed in the presence of glucose. Financial support: IFS, CNPq, CAPES and FUNAPE/UFG

\subsection{4 - ELECTROTRANSFORMATION OF PARACOCCIDIOIDES BRASILIENSIS: THE CHALLENGE OF GENE REPLACEMENT AND RNA INTERFERENCE \\ Morais, F. V. ${ }^{1}$; Nobrega, F. G. ${ }^{2}$ \\ ${ }^{1}$ Univap - IP\&D; ${ }^{2}$ Univap - IP\&D}

Introduction and Objectives: The temperature-dependent dimorphic fungus Paracoccidioides brasiliensis is responsible for paracoccidioidomycosis (PCM) in humans, an endemic disease in Latin American countries. Currently, the aim of many studies is to develop an efficient method of genetic transformation of $P$. brasiliensis in order to increase the knowledge on this pathogen. In this work we show preliminary results of the genetic transformation of the yeast form of $P$. brasiliensis by electroporation using different strategies: gene replacement and RNA interference (RNAi). The target gene chosen for both strategies was the orotidine-5'-phosphate decarboxylase gene (PbrURA3). The hygromycin B resistant gene was used as molecular marker for gene replacement and, to observe the RNAi of the transcript of PbrURA3, 5' Fluorotic acid (5'-FOA) was used to select the transformants. Methods and Results: P. brasiliensis cells from five isolates ( $\mathrm{Pb} 339, \mathrm{~Pb} 18, \mathrm{~Pb} 1925, \mathrm{PbAP}$ and $\mathrm{Pb} 608)$ were tested in presence of different concentrations of hygromycin $\mathrm{B}(25,50$, 100 and $2001 / 4 \mathrm{~g} / \mathrm{mL})$ and $5^{\prime}$ FOA $(0,5,1,0$ and $1,5 \mathrm{mg} / \mathrm{mL})$. In all cases, no growth was observed at $501 / 4 \mathrm{~g} / \mathrm{mL}$ hygromycin $\mathrm{B}$ or at $0,5 \mathrm{mg} / \mathrm{mL} 5^{\prime}$-FOA, except for PbAP, that grew at $501 / 4 \mathrm{~g} / \mathrm{mL}$ hygromycin $\mathrm{B}$. The electrotransformation was performed in a Gene Pulser Xcell electroporation system (BIO-RAD), with $2 \times 10^{7}$ viable yeast cells in $2001 / 4 \mathrm{~L}$ of $1 \mathrm{M}$ mannitol, under constant conditions $(1000 \mathrm{~V}$ or $750 \mathrm{~V}, 251 / 4 \mathrm{~F}$ and $600 \&$ !). After electroporation the cells were immediately spread in YPD plates and incubated at $37^{\circ} \mathrm{C}$. Hygromycin B or 5 FOA were added mixed on a top agar $24 \mathrm{~h}-48 \mathrm{~h}$ after electroporation. The experiment was done with all isolates, but only $\mathrm{Pb} 18$ and $\mathrm{Pb} 608$ resulted in viable transformants resistant to either hygromycin B or 5'FOA selection, which were recovered 30 days post electroporation. Transformants were maintained for about 20 passages in selective medium, then for about 30 days in medium without selection and returned to the selective medium for more 2 passages. Significant differences were observed in growth and sensitivity to hygromycin B and 5'FOA among transformants. Conclusion: The transformation of Paracoccidioides brasiliensis is feasible and the results suggest that this microorganism have a functional mechanism involved in RNAi, since transformed cells were resistant to 5'-FOA. We are investigating the PbrURA3 replacement in the genome. Financial support: FAPESP and $\mathrm{CNPq}$ 
08.025 - HETEROLOGOUS EXPRESSION AND PURIFICATION OF THE RECOMBINANT CATALYTIC SUBUNIT OF $\beta$-1,3-GLUCAN SYNTHASE OF PARACOCCIDIOIDES BRASILIENSIS

Tomazett, P. K. ${ }^{1}$; Faria, F. P. ${ }^{2}$; Santana, L. A. S. ${ }^{3}$; Soares, C. M. A. ${ }^{4}$; Pereira, M. ${ }^{5}$

${ }_{1,2,3,4,5}$ UFG - Departamento de Bioquímica e Biofísica

Introduction and objectives: Paracoccidioides brasiliensis is the etiological agent of paracoccidioidomycosis, a systemic life-threatening mycosis that affects the rural population of Central and South America. The fungus occurs as two morphological stages, mycelium and yeast. Glucans, chitin and proteins compose the cell wall of fungus. In the yeast form a structural change from $\beta$-glucan to $\alpha$-glucan polymer is observed in the $P$. brasiliensis cell wall, when compared with mycelium. The $\beta$-1,3-glucan polymer possibly gives shape to the cell and its synthesis, which occurs at the plasma membrane, may be the result of the $\beta-1,3-$ glucan synthase enzyme avtivity. In $P$. brasiliensis just one gene homologue of $\beta$-1,3-glucan synthase $(P b F K S 1)$ has been characterized. $P b F K S 1$ presents an important putative catalytic subunit that probably is responsible for the protein activity. The $\beta$-1,3-glucan synthase catalytic region from Aspergillus fumigatus has been expressed in Escherichia coli. In P. brasiliensis, this region, $P b F k s p c$, corresponds to a hydrophilic domain with 588 amino acids. Our group has been working in the study of proteins involved on cell wall metabolism of $P$. brasiliensis to use as targets for antifungals. Here we report the heterologous expression of this conserved catalytic hydrophilic domain of $P$. brasiliensis. Methods and results: The region $P b F k s p c$ was amplified from $P b F K S 1$ gene by PCR using primers added of the restriction enzymes sites. The heterologous expression of $P b$ Fkspc was undertaken in E. coli, strain BL-21, by using the expression plasmid pGEX-4T3. PbFkspc was cloned into the EcoRI/NotI site of the vector in fusion with glutathione S-transferase (GST). Isopropyl-b-Dthiogalactopyranoside (IPTG) was added to induce the recombinant protein expression. The solubilized enzyme was obtained by treatment with Sarkosyl and sonication. The soluble extract was bound to glutathione-Sepharose 4B beads and afterwards the fusion protein was digested with thrombin. After digestion, the fusion protein with a molecular size of $88 \mathrm{kDa}$ was released a polypeptide of $54 \mathrm{kDa}$, corresponding to the expected size for $P b F \mathrm{Fspc}$. The recombinant protein was inoculated into mice for production of polyclonal antibodies anti$P b F k s p c$. Conclusion: In this work we obtained recombinant $P b F k s p c$, which makes possible the production of the polyclonal antibody anti- $P b F k s p c$. Immunological analysis, citolocalization and enzymatic assays are being performed. Financial support: IFS, CAPES, CNPq and FUNAPE-UFG

\subsection{6 - CHITINASE FROM PARACOCCIDIOIDES BRASILIENSIS:} MOLECULAR CLONING, STRUCTURAL, PHYLOGENETIC, EXPRESSION AND ACTIVITY ANALYSIS

Bonfim, S. M. R. C. ${ }^{1}$; Cruz, A. H. S. ${ }^{2}$; Jesuino, R. S. A. ${ }^{3}$; Ulhoa, C. J. ${ }^{4}$; Molinari-Madlum, E. E. W. I. ${ }^{5}$; Soares, C. M. A. ${ }^{6}$; Pereira, M. ${ }^{7}$

${ }^{1,2,4,7}$ Universidade Federal de Goiás - Departamento de Bioquímica e Biofísica; ${ }^{3}$ Universidade Federal de Goiás - Department of Biochemistry and Molecular Biology; ${ }^{5}$ Universidade Federal de Goiás - Departamento de Imunologia e Patologia Geral; ${ }^{6}$ UFG - Department of Biochemistry and Molecular Biology

Introduction and Objectives: Fungi are the causative agents of a wide range of human pathogenesis. One of the most prevalent fungi in Latin America is Paracoccidioides brasiliensis. Enzymes involved in the cell wall metabolism have been approached as interesting targets to be explored to the design of specific antifungal agents, since this structure is absent in human. In dimorphic fungi, the transition of phases involves changes in the cell wall composition. An increase in chitin levels in parasitic phases is detected in Candida albicans and $P$. brasiliensis, hyphae and yeast-like, respectively, defining a cell wall thickness to the fungus inside the host. Our aim is molecular cloning, structural, phylogenetic, expression and activity analysis of a P. brasiliensis chitinase. Methods and Results: A cDNA encoding a chitinase ( $P b c t s 1)$ was cloned by screening a cDNA library from yeast cells of $P$. brasiliensis. The cDNA consists of $1888 \mathrm{bp}$ and encodes an ORF of $1218 \mathrm{bp}$ corresponding to a protein of $45 \mathrm{kDa}$ with 406 amino acid residues. $P b C T S 1$ belongs to family 18 and to fungal/bacterial class. Southern blot analysis indicated that Pbctsl is a single copy. Phylogenetic analysis with $P b C T S 1$ and other chitinases point to the possibility of several chitinases to be grouped based in specialized functions, which may reflect the multiple and diverse roles played by fungi chitinases. $P b C T S 1$ presents a complex structure of domains that could imply in multi functionality. Although PbCTS1 does not seem to present chitin-binding domains and serine/ threonine/proline-rich regions, the immunoglobulin C-Type domain could propitiate interaction with the chitin chain during catalysis. Glycosyl hydrolase activity was evaluated and the results demonstrated that $P$. brasiliensis is able to produce and secrete these enzymes mainly during transition from yeast to mycelium. The addition of chitin increased the activity of chitinase found in the medium. $P b C$ TS 1 presents an Aamy domain indicating the possibility of alpha amylase activity. The presence of an endocytic signal in the deduced protein suggests that it could be secreted by a vesicular nonclassical export pathway. The Pbcts1 expression in mycelium, yeast, during differentiation from mycelium to yeast and in yeast cells obtained from infected mice suggests the relevance of this molecule in $P$. brasiliensis electing $P b C T S 1$ as an attractive drug target. Conclusion: Here we report the molecular cloning, structural and phylogenetic analysis, as well as the expression and activity analysis of PbCTS1, which is expressed in mycelium, yeast, during differentiation from mycelium to yeast cells obtained from infected mice. In addition PbCTS1 presents motifs that indicate its probable bifunctionality and secretion to into the medium. Financial support: IFS, CNPq, CAPES and FUNAPE/UFG

\subsection{7 - CHARACTERIZATION OF A SERINE PROTEINASE FROM PARACOCCIDIOIDES BRASILIENSIS ACCUMULATED DURING THE INFECTIVE PROCESS}

Parente, J. A. ${ }^{1}$; Costa, M. ${ }^{2}$; Castro, N. S. ${ }^{3}$; Felipe, M. S. S. ${ }^{4}$; Pereira, M. ${ }^{5}$; Deepe Jr., G. S. ${ }^{6}$; Soares, C. M. A. ${ }^{7}$

1,2,3,3,7UFG - Department of Biochemistry and Molecular Biology; ${ }^{4} \mathrm{UnB}$ - Departament of Cell Biology; ${ }^{6}$ University of Cincinnati - Division of Infectious Disease

Introduction and Objectives: Paracoccidioides brasiliensis is a dimorphic fungus that alternates between a mycelium phase in the free environment and a yeast phase in the human host. Primary infection starts in the lungs after inhalation of fungal propagules. Active paracoccidioidomycosis is estimated to develop in approximately $2 \%$ of the infected individuals representing a serious public health challenge. $P$. brasiliensis expresses some molecules that account for its ability to evade efficiently the host protective immune system and proteases should be included in this group. Particularly, serine proteases use a catalytic serine residue located in the active site to attack the peptide bond of the substrate. Pathogenic microorganisms use proteases to weaken and invade their hosts. In this work, we have isolated, characterized and cloned a cDNA encoding a serine protease homologue. Also the expression profile in yeast cells obtained from experimental infection in mice and the protein heterologous expression had been performed. Methods and Results: A $0,5 \mathrm{~Kb}$ expressed sequence tag (EST) encoding a probable serine protease was obtained in the Transcriptome Project database (http://www.biomol.unb.br/Pb) and used as a probe in the screening of a yeast cDNA library constructed with RNAs from yeast cells of $P$. brasiliensis recovered from liver of infected mice. The complete cDNA ( $P b s p)$ with $1,5 \mathrm{~Kb}$ was obtained, sequenced and deposited in GenBank (accession number AY319300). The search for similarity was conducted using the BLASTx program (http://www.ncbi.nlm.nih.gov/). Domains and predicted active sites were screened using the ProfileScan (http://hits.isb-sib.ch/cgi-bin/PFSCAN). The complete cDNA of $1,5 \mathrm{~Kb}$ encodes a predicted protein of $53 \mathrm{KDa}(\mathrm{PbSP})$ and $\mathrm{pI}$ of 6,12 . A probable signal peptide was found between aminoacids 1-17, with possible cleavage site between aminoacids 16 and 17. This cDNA was cloned into an expression vector, which was used to transform Escherichia coli cells for heterologous expression of the recombinant protein. The expression profile of $P b S P$ was obtained by Northern blot analyzes using RNAs obtained from in vitro cultured $P b 01$ yeast cells and $P b 01$ yeast cells recovered from infected mice. The cognate transcript was substantially increased in the second condition. Conclusions: The analysis of the cDNA sequence demonstrated homology with serine proteases of other fungi. The predicted protein sequence shows the presence of a catalytic triad (DHS), well conserved in the subtilase family of serine proteases. The high expression of the cDNA during the experimental infective process in B10A mice suggests the importance of this protease to the fungus infective pathway. Financial support: MCT/CNPq and CAPES.

\subsection{8 - HETEROLOGOUS EXPRESSION OF A RECOMBINANT PEROXISOMAL CATALASE OF PARACOCCIDIOIDES BRASILIENSIS}

Bailao, A. M. ${ }^{1}$; Mendonça, Y. A. ${ }^{2}$; Felipe, M. S. S. ${ }^{3}$; Moreira, S. F. I. ${ }^{4}$ Pereira, M. ${ }^{5}$; Deepe Jr., G. S. ${ }^{6}$; Soares, C. M. A.

${ }_{1,2,4,5,7}$ UFG - Department of Biochemistry and Molecular Biology ; ${ }^{3}$ UnB - Department of Cell Biology; ${ }^{6}$ University of Cincinnati - Department of Molecular Genetics, Biochemistry \& Microbiology

Introduction and Objectives: Paracoccidioides brasiliensis is a human pathogenic fungus that constitutes a major medical problem in Latin America. The microorganism is the etiological agent of Paracoccidioidomycosis (PCM), a systemic disease with high prevalence in the rural population. P. brasiliensis presents thermal dimorphism. The fungus grows in a mycelial phase at $23-26{ }^{\circ} \mathrm{C}$ and as yeast at $35-37{ }^{\circ} \mathrm{C}$. The conversion from mycelium to yeast constitutes the main step for the disease establishment. An important aspect in the disease establishment is the fungus potential in modulating the host immune system. Catalases (E.C. 1. 11.1.6) are antioxidant proteins among aerobic organisms and protect cells agains oxidative damage caused by hydrogen peroxide produced by the phagocytes cells of the host. Catalases which are responsible for the conversion of hydrogen peroxide to $\mathrm{H}_{2} \mathrm{O}$ and $\mathrm{O}_{2}$ are immunodominant antigens and putative virulence factors in several pathogens. The production of catalases is one of the strategies used by microorganisms, including $P$ brasiliensis, to react against the toxicity of oxidants, which are produced in response to the infection. The main objective of this project is to produce the recombinant catalase P. Methods and Results: A cDNA sequence identified as a peroxisomal catalase was obtained from a cDNA library. This cDNA presents $1920 \mathrm{bp}$, coding for a 504 amino-acid protein with a predicted molecular mass of $56,88 \mathrm{kDa}$ and $\mathrm{p} I$ of 6.50 . The deduced protein presented homology to the peroxisomal catalases of organisms. Oligonucletides (CAT1 and CAT2) were constructed for the PCR amplification of the complete cDNA. The PCR products were subcloned into TOPO TA ${ }^{\circledast}$ (Invitrogen, CA, USA). The recombinant plasmid was digested with $B a m H \mathrm{I}$ and $N o t \mathrm{I}$ for cloning into $\mathrm{pET}^{\circledR}{ }^{\circledR}$-19B (Novagen, Madison, WI). Heterologous expression of the recombinant catalase was induced by the addition of IPTG in the growth medium. The induction process was carried out at $37^{\circ} \mathrm{C}$ overnight. The recombinant protein was purified. Conclusion: Functional studies are under progress. The cloning of the cDNA and the heterologous expression of the recombinant peroxisomal catalase may provide the analysis of the role of the catalase of $61 \mathrm{kDa}$ in the host immune response, as well as functional studies concerning to the roles of the protein in the fungus P. brasiliensis. Financial support $\mathrm{CNPq} / \mathrm{MCT}$ 
08.029 - ANALYSIS OF THE TRANSCRIPTOME OF PARACOCCIDIOIDES BRASILIENSIS DURING THE INFECTIVE PROCESS

Costa, M. ${ }^{1}$; Martins, W. S. ${ }^{2}$; Meirelles, G. V. ${ }^{3}$; Mendonça, Y. A. ${ }^{4}$; Moreira, S. F. I. ${ }^{5}$; Parente, J. A. ${ }^{6}$; Bailao, A. M. ${ }^{7}$; Borges, C. L. ${ }^{8}$; Fiuza, R. B. ${ }^{9}$; Faria, F. P. ${ }^{10}$; Felipe, M. S. S. ${ }^{11}$; MolinariMadlum, E. E. W. I. ${ }^{12}$; Pereira, M. ${ }^{13}$; Soares, C. M. A. ${ }^{14}$

1,3,4,5,6,7,8,10,13,14UFG-Department of Biochemistry and Molecular Biology; ${ }^{2,9}$ Universidade Católica de Goiás - Department of Computer Science; ${ }^{11} U n B$ - Department of Cell Biology; ${ }^{12} U F G$ Department of Immunology and General Pathology

Introduction and Objectives: Paracoccidioides brasiliensis is a dimorphic human pathogenic fungus, the ethiological agent of paracoccidioidomycosis (PCM), a systemic mycosis with restricted geographical distribution in Latin America. The infection is acquired by the inhalation of airborne microconidia, which reach the pulmonary alveolar epithelium and differentiate into the parasitic yeast form. Understanding of the complex interactions between the fungus and its host must include the identification of gene expression patterns during infection. The sequencing of cDNAs generating ESTs (Expressed Sequence Tags) provides information on gene expression during specific conditions. The objective of this work is to describe a transcriptome of $P$. brasiliensis yeast cells recovered from liver of infected mice. Methods and Results: B10.A mice were intraperitoneally inoculated with $5 \times 10^{6}$ yeast cells of $\mathrm{Pb} 01$ (ATCC MYA-826). The animals were sacrificed at the $7^{\text {th }}$ day after infection and the liver was removed. Infected liver was cultivated for 14 days and total RNA was extracted. Poly (A) + mRNA was obtained and a unidirectional cDNA library was constructed with the Superscript Plasmid System. In this study, a total of 5.243 sequences, clustering into 1.029 contigs and 643 singlets were obtained. The predominant transcripts were identified as Heat Shock Proteins (HSPs 70, 60, 30, 90, 88, 82), CLPA and DNA J, all probably involved in the stress response. Proteinases (Aspartyl proteinase, Aspartyl aminopeptidase, Serine proteinase, CaaX prenyl protease and CaaX farnesyltransferase alpha subunit) were also highly redundant. Many sequences showed no matches with known protein sequences and hypothetical proteins were found. The contigs and singlets were classified into functional groups by annotation using a pipeline that includes automatic processing Conclusion: Analyses and functional categorization of the transcripts of $P$. brasiliensis during the infective process will contribute for the knowledge of a number of expressed genes potentially involved in the infective process as well as for the understanding of the pathogenicity of this fungus. Financial support: Capes; CNPq / MCT.

\subsection{0 - PARACOCCIDIOIDES BRASILIENSIS TRANSFORMATION:}

\section{ENLARGING THE GENETIC TOOLBOX}

Soares, R. B. A. ${ }^{1}$; Gomez, F. J. ${ }^{2}$; Soares, C. M. A. ${ }^{3}$; Deepe Jr., G. S..$^{4}$; Smulian, A. G. ${ }^{3}$

${ }^{1,3}$ UFG - Department of Biochemistry and Molecular Biology; ${ }^{2,4,5}$ University of Cincinnati, College of Medicine, Ohio, USA, 45267-0560 - Division of Infectious Diseases, Department of Internal Medicine

Introduction and Objectives: Fungal genetic manipulation is a technique well described for Saccharomyces cerevisiae, Neurospora crassa and Aspergillus nidulans, and has contributed to the understanding of the biology and evolution of these organisms. This methodology has been also applied for human pathogenic fungi like Candida albicans, Cryptococcus neoformans and Histoplama capsulatum, allowing studies of genes involved in pathogenesis and virulence in these organisms. In this experimental work we developed a transformation system in Paracoccidioides brasiliensis that provides a means for genetic manipulation of this fungus. The success of this technique will be to enhance understanding of its biology, gene function, differentiation, and host-pathogen interaction including virulence and pathogenicity. As an application of this technology, we studied the molecular requirements for adhesion between transgenic, fluorescent $P$. brasiliensis and RAW cells, a murine macrophage cell line. Methods: We describe here the transformation of the yeast phase of $P$ brasiliensis (ATCC-MYA 826) with Agrobacterium tumefaciens carrying the vector pCB301UGFP. The microorganisms were co-cultivated for 3 days. Transformants were selected by incubation on selective media containing hygromicin B and cefotaxime in order to kill nontransformants and Agrobacterium. The expression of the transgenic GFP was detected by fluorescent and confocal microscopy. GFP P. brasiliensis were incubated with RAW cell monolayers in the presence of culture media, EDTA or anti-CD18 monoclonal antibodies Inhibition of adhesion was quantified by fluorescent microscopy. Results: From an initial inoculum of $10^{7}$ P. brasiliensis yeast cells we typically obtained 20 hygromycin B resistant colonies. The expression of GFP was variable among the transformants, suggesting an effect of the point of insertion in P. brasiliensis genome, $50 \%$ of the transformants showed intense fluorescence. $P$. brasiliensis adhesion to RAW cells is dependent on the presence of divalent cations, and is inhibited by CD18 specific antibodies. Conclusions: Agrobacterium mediated transformation is an effective and efficient method of gene transfer in P. brasiliensis. It is suitable for the expression of heterologous transgenes, and, by random insertion, mutagenesis and gene deletion. Transgenic $P$. brasiliensis is a useful tool to study interaction between the pathogen and the host cells. Financial support: $\mathrm{CNPq}$
08.031 - ANALYSIS OF TRANSCRIPTS OF PARACOCCIDIOIDES BRASILIENSIS DURING THE FUNGUS DIMORPHIC TRANSITION

Bastos, K. P.'; Bailao, A. M. ${ }^{2}$; Borges, C. L. ${ }^{3}$; Moreira, S. F. I. ${ }^{4}$; Parente, J. A. ${ }^{5}$; Fiuza, R. B. ${ }^{6}$; Faria, F. P. ; Felipe, M. S. S. ${ }^{8}$; Pereira, M. ${ }^{9}$; Martins, W. S. ${ }^{10} ;$ Soares, C. M. A. ${ }^{11}$

1,2,3,4,5,7,9,11 UFG - Department of Biochemistry and Molecular Biology ; ${ }^{6}$ Universidade Católica de Goiás - Department of Computer Science ; ${ }^{8}$ UnB - Departament of Cell Biology; ${ }^{10}$ Universidade Católica de Goiás - Department of Computer Science

Introduction and Objectives: Paracoccidioides brasiliensis causes paracoccidioidomycosis (PCM), a human systemic disease, which is confined to Latin America. The pathogen is a dimorphic fungus, which, under the influence of temperature, changes from a mycelial $(\mathrm{M})$ to a yeast $(\mathrm{Y})$ form. The mycelium to yeast transition has been shown to be essential for the establishment of the infection, although the precise molecular mechanisms of dimorphism in P. brasiliensis are still poorly understood. In this work we constructed a cDNA library to characterize the transcriptome of $P$. brasiliensis during the dimorphic transition, from mycelium to yeast. Methods and Results: Total RNA of $P$. brasiliensis, isolate $P b 01$ (ATCC-MYA-826), from cells in transition from mycelium-toyeast after $22 \mathrm{~h}$ of the temperature shift $\left(22\right.$ at $\left.37^{\circ} \mathrm{C}\right)$ was isolated by the Trizol method. Polyadenylated RNA was purified by using oligo (dT)-cellulose, and a unidirectional cDNA library was constructed in plasmid pCMVSport 6.0 (Invitrogen, CA, USA). We obtained 1423 expressed sequence tags (ESTs) of high quality that were assembled into 183 contigs and 414 singlets. The ESTs were automatically analyzed and assembled using the programs Phred, Crossmatch and CAP3. The resulting contigs and singlets were annotated using a pipeline that included automatic processing. The detected ESTs were functionally classified by similarity to known genes. We have identified several genes potentially involved in cellular metabolism, cellular structure, stress response, proteins metabolism, RNA synthesis, among others. Some clusters show similarity to hypothetical proteins or have no significant similarity to any proteins in the databases. Computer subtraction analysis reveled some putative specific sequences of the dimorphic transition. Furthermore, we have analyzed the expression of genes during the mycelium-yeast transition by reverse transcription-PCR and Northern blot. Conclusion: Comparative analyses and functional categorization of the transcribed genes during mycelium to yeast transition in $P$. brasiliensis allowed the identification of some new genes as well as provided information and a base for future research in the morphological differentiation of $P$. brasiliensis. Theses studies may provide new insights into the pathogenesis, virulence and mechanisms involved during the pathogen-host interaction. Financial support: $\mathrm{CNPq} / \mathrm{MCT}$

\subsection{2 - REPRESENTATIONAL DIFFERENCE ANALYSIS (RDA) FOR THE DETECTION OF DIFFERENTIAL GENE EXPRESSION IN ISOLATES OF PARACOCCIDIOIDES BRASILIENSIS.}

Santos, M. O. ${ }^{1}$; Borges, C. L. ${ }^{2}$; Bailao, A. M. ${ }^{3}$; Fiuza, R. B. ${ }^{4}$; Felipe, M. S. S. ${ }^{5}$; Hahn, R. C. ${ }^{6}$; Martins, W. S. ${ }^{7}$; Pereira, M. ${ }^{8}$; Soares, C. M. A. ${ }^{9}$

$1,2,3,8$ Universidade Federal de Goiás - Department of Biochemistry and Molecular Biology; ${ }^{4}$ Universidade Católica de Goiás - Department of Computer Science ; ${ }^{5} \mathrm{UnB}$ - Departament of Cell Biology; ${ }^{6}$ Universidade Federal de Mato Grosso - Hospital Universitário Julio Muller ${ }^{7}$ Universidade Católica de Goiás - Department of Computer Science; ${ }^{9}$ Universidade Federal de Goiás - Department of Biochemistry and Molecular Biology

Introduction and Objectives: Paracoccidioides brasiliensis is the causative agent of Paracoccidioidomycosis (PCM) the most prevalent systemic mycosis in Latin America. The fungus presents thermal dimorphism and the transition from mycelium to yeast in the main event in the infection establishment. Different clinical manifestations of PCM can be related to characteristics of isolates. This study has the objective of identifying genes differentially expressed in isolates obtained from patients with different clinical manifestations of PCM Methods and Results: P. brasiliensis isolates PbABS (collected from patients with oral lesions) and Pb561 (collected from patients with pulmonary and ganglionar lesions) have been grown in the yeast phase at $37^{\circ} \mathrm{C}$, for 7 days and total RNAs were obtained. The cDNAs were synthesized using reverse transcriptase. Both, $P b A B S$ and $P b 561$ were used as testers and drivers, in the identification of specific genes related to each isolate. Differential products were obtained by two rounds of subtraction and amplified by PCR reactions. The PCR products were cloned into pGEM-T-Easy (Promega ${ }^{a}$, Madison). Positive clones were submitted to sequencing using a Mega BACE 1000 DNA sequencer (Amersham Biosciences ${ }^{\hat{a}}$ ). Sequences of 384 clones were clustered into contigs and singletons. A preliminary analysis using the BLASTX algorithm identified genes putatively involved in hydrolysis and absorption of lipids, in biosynthesis and transport of amino acids, in the stability of the cell wall, in biogenesis of perixomes, and others. The resulting contigs and singletons will be annoted using a pipeline (Phred, Crossmatch and CAP3). Comparative analysis of the expressed sequence tags (ESTs) will be performed by using the PHOREST program. (https:// www.biol.lu.se/phorest). Conclusion: cDNA Representational difference analysis (cRDA) provides a powerful technique for the identification of differences between two mRNA populations. Both isolates of $P$. brasiliensis are virulent and cause different clinical manifestations of PCM. Therefore, overexpressed genes could be potentially involved in events leading to different types of clinical manifestations of PCM. Financial support: MCT/ CNPq - FUNAPE 
08.033 - EVALUATION OF THE ACTION OF EUGENIA UNIFLORA EXTRACTS ON GROWTH AND GENE EXPRESSION OF PARACOCCIDIOIDES BRASILIENSIS

Dias Santos, G. ${ }^{1}$; Ferri, P.H. ${ }^{2}$; Santos, S.C. ${ }^{2}$; Silva, M.R.R. ${ }^{3}$; Bao, S.N. ${ }^{4}$; Soares, C.M.A. ${ }^{1}$; Pereira, M. ${ }^{1}$

${ }^{1}$ Universidade Federal de Goiás - Bioquímica e Biologia Molecular; ${ }^{2} U F G$ - Departamento de Química Analítica; ${ }^{3}$ UFG - Departamento de Microbiologia, Imunologia, Parasitologia e Patologia; ${ }^{4} U n B$ - Departamento de Biologia Celular.

INTROCUCTION AND OBJECTIVES: Paracoccidioides brasiliensis, the causative agent of Paracoccidioidomycosis (PCM), is a thermal dimorphic fungus, which manifests the yeast-like form at $36^{\circ} \mathrm{C}$ and mycelia at $28^{\circ} \mathrm{C}$. The disease is endemic in Latin America, where it is believed that up to 10 million individuals could be infected. Crude extracts of plants and their fractions have been used in the treatment of chronic diseases or to maintain a better health condition. In the literature there are descriptions of the Brazilian savannah plants extracts rich in tannins and alkaloids with several antimicrobial activities. Tannins are water-soluble polyphenols that complex with proteins, polysaccharides and alkaloids and present several biological activities. Eugenia uniflora is a savannah plant used in popular medicine and presents oenotein B as a major molecule in its leaves aqueous extract. Our objectives are to study the action of the non-polar fraction of extracts from E. uniflora in yeast cells of $P$. brasiliensis, as well as analyze the extracts action on the transcripts of malate synthase, isocitrate lyase, chitinase, 1,3- $\beta$-glucan synthase, glucanase, c2 4 sterol methyltransferase by using the RT-PCR methodology. In addition, electronic microscopy has been used to detect possible cellular damage in the treatment condition. METHODS AND RESULTS: By using high performance liquid chromatography we isolated and characterized the main chemical component of E. uniflora, the oenotein B. The growth of yeast cells was analyzed in the presence of aqueous extract of leaves from E. uniflora (125 $\mathrm{mg} / \mathrm{mL}$ to $1 \mathrm{~g} / \mathrm{mL}$ ), in McVeigh-Morton (MVM) minimum medium. The minimal inhibitory concentration (MIC) was obtained by using the microdilution method described on NCCLS M27. The yeast cells were maintained for 15 days at $36^{\circ} \mathrm{C}$ and counted in a Neubauer chamber. The results were analyzed in the Microcal Origin 5.0. The growth of the yeast cells was inhibited by $75 \%$ in the presence of the oenotein B fraction $(500 \mu \mathrm{g} / \mathrm{mL})$. Total RNAs were obtained from control and yeast cells grown in the presence of the non-polar fraction of $E$. uniflora. RT-PCR and electronic microscopy analysis were performed ten days after treatment of the cells. The results indicate that the $1,3-\beta$-glucan synthase transcripts were inhibited by the soluble fraction containing oenotein B. Electronic microscopy analysis suggest morphological alterations on yeast cells of $P$. brasiliensis, such as depression on surface. CONCLUSION: Extracts from E. uniflora inhibited growth of the yeast cells of P. brasiliensis. Our results showed that the most effective dosage is $500 \mu \mathrm{g} / \mathrm{mL}$. In addition, the $1,3-\beta$ glucan synthase transcripts decreased with the treatment. Morphological alterations, such as depression on surface were observed in yeast cells of $P$. brasiliensis, indicating a possible action of the soluble fraction containing oenotein $\mathrm{B}$ on cell wall metabolism. FINANCIAL SUPPORT: IFS, CNPq and FUNAPE/UFG.

08.034 - DETECTION AND SELECTION OF MICROSATELLITES IN THE GENOME OF PARACOCCIDIOIDES BRASILIENSIS AS MOLECULAR MARKERS FOR CLINICAL AND EPIDEMIOLOGICAL STUDIES

Nascimento, E. ${ }^{1}$; Martinez, R. ${ }^{2}$; Lopes, A. R. ${ }^{3}$; Sousa Bernardes, L. A. ${ }^{4}$; Barco, C. ${ }^{5}$; Goldman, M. H. ${ }^{6}$; Taylor, J. W. ${ }^{7}$; McEwen, J. G. ${ }^{8}$; Nobrega, M. P. ${ }^{9}$; Nobrega, F. G. ${ }^{10}$; Goldman, G. ${ }^{11}$ ${ }^{1,3,4}$ FCMRP - USP - Biociências; ${ }^{2}$ FMRP - USP - Clínica Médica; ${ }^{5,9}$ UNIVAP - Biologia Molecular; ${ }^{6}$ FCMRP - USP - Biologia; ${ }^{7}$ University of Califórnia, USA - Plant and Microbial Biology; ${ }^{8}$ Corporación para Investigaciones Biológicas, Colombia - Cellular and Immunogenetics Group; ${ }^{10}$ UNIVAP - IP\&D; ${ }^{11}$ FCMRP - USP - Biologia Molecular

Introduction and Objectives: Paracoccidioides brasiliensis, a thermodimorphic fungus, is the causative agent of the prevalent systemic mycosis in Latin America, paracoccidioidomycosis. Here, we describe the microsatellite patterns observed in a collection of $P$. brasiliensis Random Sequence Tags (RSTs). Methods and Results: We identified 1,117 microsatellite patterns in about $3.8 \mathrm{Mb}$ unique sequences $(0.47 \%$ of the total DNA taken to the analysis). The majority of these microsatellites $(87.5 \%)$ are found in noncoding sequences. We used two polymorphic microsatellites located on noncoding and coding sequences, as well as two microsatellites located on introns as molecular markers to discriminate $P$. brasiliensis isolates looking for relationships between the genetic background of the strains and the type of human disease they cause. Conclusion: We did not observe any correlation between the clinical form of human paracoccidioidomycosis and four SSR (simple sequence repeat) patterns analyzed. Financial support: FAPESP, CAPES and CNPq

\subsection{5 - CLONING OF THE DNA ENCODING A $\beta$-1,3-ENDOGLUCANASE} FROM PARACOCCIDIOIDES BRASILIENSIS

Cruz, A. H. S. ${ }^{1}$; Bonfim, S. M. R. C. ${ }^{2}$; Rodrigues Silva, C. ${ }^{3}$; Soares, C. M. A. ${ }^{4}$; Pereira, M. ${ }^{5}$ ${ }^{I} U F G$ - Bioquímica e Biofísica; ${ }^{2,3,5} U F G$ - Departamento de Bioquímica e Biofísica; ${ }^{4} U F G$ Department of Biochemistry and Molecular Biology

Introduction and Objectives: Paracoccidioidomicose (PCM), caused by Paracoccidioides brasiliensis, is an important human mycosis restricted to Latin America where it causes important morbidity and mortality, among male agriculturists. The fungus shows a thermal dimorphism, growing as mycelium at $22^{\circ} \mathrm{C}$ and yeast at $37^{\circ} \mathrm{C}$. The change from the mycelial to yeast is crucial for the establishment of the infection in the human host. Infection typically occurs by inhalation of fungal propagules, followed by the thermally regulated transition to the parasitic yeast phase. The cell wall of $P$. brasiliensis is an essential structure since it is involved in vital processes of the cell, such as defense, cell division and growth. The main constituents of the cell wall of P.brasiliensis are chitin, glucans, lipids and proteins. The main polysaccharide of the yeast cell wall is $\beta$-glucan, whereas the polysaccharides of the mycelium wall are $\beta$-glucan and galactomannans. Enzymes involved in the cell wall metabolism, as chitinases and glucanases, have been associated to the pathogenicity and virulence. In this way are interesting targets to design specific antifungal agents, since the cell wall is absent in human. The objective of this work is cloning of the DNA encoding to $\beta-1,3$-endoglucanase of $P$. brasiliensis. Methods and Results: The partial cDNA of the $\beta-1,3$-endoglucanase was identified in the P. brasiliensis transcriptome (http:/ /www.biomol.unb.br). Computational analyses suggest that it is a $\beta$-1,3-endoglucanase belongs to the family 81 of glicosilhidrolases. Oligonucleotides were constructed and a partia cDNA of the $\beta$-1,3-endoglucanase was amplified by PCR by using a mycelia cDNA library. The probe of $509 \mathrm{bp}$ was used by in the screening of a cDNA library. Southern blot was also performed in order to define the number of genes of the $\beta-1,3$-endoglucanase gene. The analysis indicates that $\beta-1,3$-endoglucanase is not a single copy. Conclusion: Our results suggest that the clone holding the $\beta$-1,3-endoglucanase cDNA has been isolated and the presence of the homologous gene is suggested. Northern blot was performed and the results showed the presence of $\beta-1,3$-endoglucanase in $P$. brasiliensis. Financial support: IFS CNPq, CAPES and FUNAPE-UFG

\subsection{6 - CHARACTERIZATION AND HETEROLOGOUS EXPRESSION OF A} CDNA ENCODING A THIOREDOXIN HOMOLOGUE OF PARACOCCIDIOIDES BRASILIENSIS

Domingos, F. C. ${ }^{1}$; Lima, Y. A. R. ${ }^{2}$; Faria, F. P. ${ }^{3}$; Soares, C. M. A. ${ }^{4}$; Jesuino, R. S. A. ${ }^{1,2,4,5}$ UFG - Biochemistry and Molecular Biology; ${ }^{3} U F G$ - Biochemistry

Introduction and Objectives: The temperature-dependent dimorphic fungus Paracoccidioides brasiliensis is the ethiological agent of Paracoccidioidomycosis (PCM) in man, which is endemic in countries of Latin America. The cellular differentiation of $P$ brasiliensis from mycelium to yeast in the lungs is essential for the establishment of the infection. Thioredoxin (TRX), a cellular thiol, functions as a self-defense mechanism in response to environmental stimuli, including oxidative stress. TRX is required to maintain redox homeostasis in response to both reductive and oxidative stress conditions. We here report the characterization of the cDNA $P b \operatorname{trx} 1$, encoding a $P b T R X 1$ and its phylogenetic analysis, structure secondary prediction and the production and purification of the recombinant protein in Escherichia coli. After its production and purification, we intend to realize activity assays with the recombinant $P b T R X 1$. It is possible that $P b T R X 1$ may enhance survival of the $P$. brasiliensis in the host protecting the fungus against the reactive oxygen species. In this way, $P b T R X 1$ allows the development and the progress of infection in the human host. Methods and Results: The complete cDNA (Pbtrx1) (GenBank: AY376435) presented 811 nucleotides, with an open reading frame of $350 \mathrm{bp}$, encoding a protein (PbTRX1) with a predicted molecular mass of $12 \mathrm{kDa}$ and $\mathrm{pI}$ of 5.2. The PbTRX1 presents one highly conserved motif WCGPC, described as characteristic thioredoxin active site. This protein presents identities values of 62,57 and $51 \%$ to the sequences of those from Emericella nidulans, Saccharomyces cerevisiae and Candida albicans, respectively. Prediction of the $\mathrm{PbTRX}$ secondary-structure contents using the expasy program (http://www.expasy.ch) folds into a pattern characteristic of the open twisted alpha/beta ( 5 beta-sheets associated in a parallel and anti parallel manner and surrounded by 4 helices), structure already found for human thioredoxins for which the PbTRX1 shares $46 \%$ of sequence identity. Sequence analysis of the $P b$ TRX1 performed by PSORT, suggests a cytoplasmic localization of $P b$ TRX1. Phylogenetic analysis of PbTRX1 shows that $P$. brasiliensis is enclosed in the fungi clade. The expression of the PbTRX1 was undertaken in $E$. coli host strain BL21 as a fusion protein with GST using the expression vector pGEX-4T-3. The recombinant TRX was obtained by induction with IPTG and showed a molecular mass of $38 \mathrm{kDa}$, as expected for $P b$ TRX1 fusion with GST protein. Conclusion: This work reports for the first time the characterization of a complete cDNA encoding a TRX from $P$. brasiliensis. The PbTRX1 recombinant protein was efficiently expressed in E. coli and its purification is under progress The recombinant protein will be useful for studies regarding to its role in the host fungus interaction. Financial support: MCT/CNPq and FUNAPE-UFG. 
08.037 - MOLECULAR CLONING AND CHARACTERIZATION OF A MACROPHAGE INHIBITORY FACTOR HOMOLOG OF PARACOCCIDIOIDES BRASILIENSIS

Oliveira, G. C. ${ }^{1}$; Andrade, R. V. ${ }^{2}$; Maranhao, A. Q. ${ }^{3}$; Brigido, M. ${ }^{4}$

${ }^{1,3,4} \mathrm{UnB}-\mathrm{UnB}$ - Molecular Biology Laboratory ; ${ }^{2} \mathrm{UnB}$ - Molecular Biology Laboratory

Introduction: The dimorphic fungus Paracoccidioides brasiliensis is the etiological agent of paracoccidioidomycosis (PCM), a fungal disease that affects many individuals in Latin America. The mycelia found in nature constitute the infective phase that differentiates to yeast form in the human lungs to establish the infection. The fungus promotes a cell mediated immune and inflammatory pulmonary response. Macrophages are pivotal effectors cells of the innate immune system, recognizing and eliminating invasive microbial pathogens. Initially identified as a T-cell cytokine, the Macrophage Migration Inhibitory Factor (MIF) is also a macrophage cytokine and an important mediator of inflammation. From the project "Functional and Differential Genome of $P$. brasiliensis" ESTs (Expressed Sequence tags) database we discover a putative fungi homologue to the mammalian MIF. There are no reports in the literature of MIF homologues in fungi, however the sequence described in the genome of $P$. brasiliensis has sequence similarity to genes of animal and plant origin. Objective: The aim of this work is to investigate the gene encoded by the Pb MIF homolog in order to characterize its coding sequence and predicted polypeptide. Methods and Results: Two MIF related cDNA clones were fully sequenced and the predicted MIF homolog was identified. The clones are identical and the mRNA expression was restricted to the yeast form, as detected by Northern Blot. Sequence analysis indicated that the predicted amino acid sequence has a similarity of 56\% (32\% identical) with the MIF of Mus musculus. The Pb MIF CDS (coding sequence) was subcloned into bacterial expression vector (pET21) fused to a histidine tag. This CDS will be expressed in Escherichia coli to produce high levels of recombinant protein Discussion: We have detected and characterized a Pb MIF putative homolog. This is the first report of a MIF homolog among fungi and its role as cytokine mimetic may reveal new virulent factors for $P$. brasiliensis infection. During the co-evolution with immune system, pathogens must have developed relevant strategies of evasion of host response. Incorporating cytokines homologs may be a successful strategy for $P$. brasiliensis. Conclusion: The reported putative $\mathrm{Pb}$ MIF homolog may be part of a previously unknown strategy for $P$. brasiliensis survival inside the mammalian host. Therefore its further characterization may lead to new therapeutic strategies for combating PCM. Financial support: CAPES and MCT

\subsection{8 - TREATMENT OF PARACOCCIDIOIDES BRASILIENSIS WITH HYDROGEN PEROXIDE, MENADIONE AND AMINOTRIAZOL: IN VITRO EFFECTS}

Dantas, A. S. ${ }^{1}$; Felipe, M. S. S. ${ }^{2}$; Polez, V. L. P. ${ }^{3}$ Nicola, A. M. ${ }^{4}$; Campos, E. G. ${ }^{5}$

$1,2,3,4,5 n B$ - Departament of Cell Biology

Introduction and Objectives: The relevance of free radical generation and oxidative stress with regard to Paracoccidioides brasiliensis survival in vitro is being examined by our research group. The quinone menadione (vitamin K3; 2-methyl-1,4-naphthoquinone), a synthetic derivative of vitamin $\mathrm{K} 1$, is activated by cytochrome $\mathrm{P} 450$ reductase via a oneelectron reduction resulting in the formation of a semiquinone radical, which subsequently may reduce molecular oxygen to superoxide anion. Aminotriazole (3-amino-1, 2, 4-triazole) is an irreversible inhibitor of catalase. Menadione and hydrogen peroxide $\left(\mathrm{H}_{2} \mathrm{O}_{2}\right)$ were used to test $P$. brasiliensis susceptibility to oxidative stress in vitro. The effects of aminotriazole on celll viability was also examined. Methods and Results: Yeast cells were grown aerobically in YPD medium in the presence and absence of $\mathrm{H}_{2} \mathrm{O}_{2}$, menadione or aminotriazole for various periods of time (10 min-12 hours). Cells were then plated on BHI-agar medium and the colonies on each plate were counted. Cellular extracts were used to measure catalase and cytochrome c peroxidase $(\mathrm{CcP})$ enzyme activity. Catalase activity was measured by the consumption of $\mathrm{H}_{2} \mathrm{O}_{2}$ at $240 \mathrm{~nm}$ and $\mathrm{CcP}$ activity was determined by the cytochrome-c oxidation at $550 \mathrm{~nm}$. All experiments were performed in triplicate. Yeast grown to exponential phase and treated with $50 \mathrm{mM} \mathrm{H}_{2} \mathrm{O}_{2}$ presented 4-7\% cell death. Cell survival after 12 hours of treatment with $5 \mathrm{mM} \mathrm{H} \mathrm{O}_{2}$ was between $97-100 \%$. Treatment with $75 \mathrm{mM}$ menadione caused 57\% cell death. The specific activity of catalase in control cells was 5-20 fold higher than the activities found in other fungi. Catalase activity increased after treatment with 50 $\mathrm{mM} \mathrm{H} \mathrm{O}_{2}$, but remained unchanged upon treatment with $5 \mathrm{mM} \mathrm{H}_{2} \mathrm{O}_{2}$. CcP specific activity was $1.5-2$ fold higher in cells treated with 5 or $50 \mathrm{mM} \mathrm{H}_{2} \mathrm{O}_{2}$. The combined results showed that catalase and $\mathrm{CcP}$ respond promptly to $\mathrm{H}_{2} \mathrm{O}_{2}$ treatment. Survival assays using aminotriazole showed that only high doses $(>0.5 \mathrm{M})$ of this drug is capable of killing P. brasiliensis. Conclusion: The results indicated that $P$. brasiliensis is more susceptible to menadione than to $\mathrm{H}_{2} \mathrm{O}_{2}$. Aminotriazole showed low toxicity to P. brasiliensis in culture. Catalase and $\mathrm{CcP}$ seem to be of primary importance in the defense against oxidative stress in P. brasiliensis. Financial support: CNPq and Capes

\subsection{9 - MOLECULAR TYPING OF THE PARACOCCIDIOIDES BRASILIENSIS AFTER PASSAGE IN CULTURED MAMMALIAN EPITHELIAL CELLS:} CORRELATION WITH ADHESION.

Silva, J. F. ${ }^{1}$; Andreotti, P. F. ${ }^{2}$; Monteiro da Silva, J. L. ${ }^{3}$; Mendes-Giannini, M. J. S. ${ }^{4}$; Soares, C. P. 1,2,3,4,5 UNESP - Departamento de Análises Clínicas, Faculdade de Ciências Farmacêuticas Araraquara, SP - Brasil paracoccidioidomycosis (PCM), is a dimorphic fungus, which develops a mycelial form at room temperature and a multiple - budding yeast in the infected host or in culture at $37^{\circ} \mathrm{C}$. The virulence of $P$. brasiliensis can be attenuated or even lost after consecutive cycles of subculturing over long periods and reestablished after passage in animals and epithelial cell culture. The development of the randomly amplified polymorphic DNA (RAPD) technique represented a marker in the molecular characterization of diverse organisms. In the present work, we examined the use of RAPD (using primer 4 of the Kit Ready to go/Amersham Pharmacia Biotech) and the PCR fingerprinting (using minisatellite specific core sequence of the wild type phage M13 and of the microsatellite specific sequence (GACA) $)_{4}$ ) techniques to distinguish among ten isolates of $P$. brasiliensis after passage in the cultured mammalian epithelial cells and correlation with adhesion events. Methods and Results: For the adhesion assay, epithelial cells were cultured at $36,5^{\circ} \mathrm{C}$, infected with yeast forms of $P$. brasiliensis and incubated for $5 \mathrm{~h}$ at $36,5^{\circ} \mathrm{C}$. After this period of incubation, the cells were washed, fixed, stained with Giemsa and analyzed by optical microscopy. Different patterns of fungi adhesion were observed. P. brasiliensis DNA was extracted and used in the molecular typing by RAPD and PCR fingerprinting techniques. With the primer 4, we detected 4-10 bands varying from 100 to $1800 \mathrm{bp}$ We have two clusters and the strains were distributed in two groups with $60 \%$ similarity between them. (I: Pb1921R, Pb2367R and Pb2508R; II: Pb2493R and Pb1934R). P. brasiliensis $01 \mathrm{R}$ isolate presented $85 \%$ genomic identity with $P$. brasiliensis $1578 \mathrm{R}$ isolate (isolates from the same regions of Brazil) and only 50\% with the others. But, when we employed the microsatellite repeats (GACA), we detected 3-6 bands varying from 400 to 1800bp distributed in only one cluster $(\mathrm{Pb} 265 \mathrm{R}, \mathrm{Pb} 113 \mathrm{R}$ and $\mathrm{Pb} 1921 \mathrm{R})$ and three groups with a lower relationship. P. brasiliensis $01 \mathrm{R}$ isolate presented only $40 \%$ similarity with the others isolates. Finally, when we used M13 core sequence, the profile of 2-8 bands varying from 130 to $1800 b p$ were distributed in three clusters (I: Pb265R and Pb1921R; II: Pb113R and Pb1934R; III: Pb 2367R and Pb 2508R). P. brasiliensis 01R isolate also presented 65\% genomic identity with $P$. brasiliensis $1578 \mathrm{R}$ isolate (isolates from the same regions of Brazil) and only $35 \%$ genomic identity with the others $P$. brasiliensis isolates. Conclusion: Therefore, differences in the epithelial cell adhesion profiles and different RAPD and PCR fingerprinting profiles were detected. Financial support: PIBIC/ CNPq ; PADC-FCF and FAPESP

\subsection{0 - DIVERGENCE POPULATION GENETICS OF THE THREE PHYLOGENETIC SPECIES OF PARACOCCIDIOIDES BRASILIENSIS} Matute, D. R. ${ }^{1}$; Quesada, L. M. ${ }^{2}$; Restrepo, A. ${ }^{3}$; Taylor, J. W. ${ }^{4}$; Mcewen, J. G.

${ }^{1}$ Unidad de Biología Celular e Inmunogenética, Corporación para Investigaciones Biológicas, Medellín, Colombia - Laboratorio de Micología Medica y Ambiental. Universidad de Los Andes, ${ }^{2}$ Laboratorio de Micología Medica y Ambiental. - Universidad de Los Andes; ${ }^{3}$ Unidad de Biología Celular e Inmunogenética - Corporación para Investigaciones Biológicas, Medellín, Colombia; ${ }^{4}$ Department of Plant and Microbial Biology - University of California, Berkeley, California 94720; ${ }_{5}^{5}$ Unidad de Biología Celular e Inmunogenética, Corporación para Investigaciones Biológicas Medellín, Colombia - Facultad de Medicina, Universidad de Antioquia, Medellín, Colombia.

Introduction: Comparative DNA sequencing data can be used to study divergence, but the relationship between DNA sequence differences and the timing of population splitting with the processes associated with population splitting can be complex. Even under the simplest models, in which an ancestral population splits into two descendant populations with no gene exchange thereafter, the amount of divergence in DNA sequences between the two populations is a complex function of the time since the split and the relative sizes of the three populations (the two descendants and the ancestral population). Whether or not gene flow has been occurring among the three phylogenetic species of $P$. brasiliensis is a question of considerable interest because it might give clues of how the speciation process took place. Methods and results: Our data indicate that $P$. brasiliensis consists of three distinct species: S1 (found in Brazil, Argentina, Paraguay, Peru and Venezuela), PS2 (found in Brazil and Venezuela) and PS3 (found only in Colombia). Two of those P. brasiliensis lineages, $\mathrm{S} 1$ and PS2, are sympatric across their range, suggesting barriers to gene flow other than geographic isolation. PS2 and PS3 constitute a monophyletic group (group composed by the ancestral specie and its descendants). S1 is a paraphyletic group that is considered the ancestor of the other two species. The data obtained in a previous study of eight regions from 5 codifying genes were analyzed according to the model of isolation with migration. We excluded those loci that showed no variation within or between the two taxa being compared in each pairwise analysis, because they are informative for this kind of analysis. The scalars of time of divergence indicate that the speciation process that gave origin to PS2 happened before the speciation process that originated PS3. The data also show that these two species have a small population size compared with the parental population. Evidence of gene flow was found in all the comparisons made for the 3 species indicating that gene exchange among the three recognized species had occurred in the recent past. Conclusions: From our analyses, S1 and PS2 appear to have been more isolated than S1 and PS3 with limited gene flow since they began to diverge. The divergence of these species appears consistent with a speciation model in which geographic isolation prevented gene flow during the separation of these species. A related riddle is why migration does not occur in a symmetric way in both the cases analyzed. Although there may be many possible explanations, given the several thousand years that have passed since the two speciation processes happened, we consider the possibility that another population, that was not sampled, may play a role in explaining our results. Financial support: This research was supported by grants from Fogarty International Research Collaboration Award (FIRCA) grant R03TW01308, Banco de la republica $\mathrm{N}^{\circ} 1785$ and by funds of CIB and CODI, U de. Antioquia. 
08.041 - MOLECULAR CHARACTERIZATION OF THE HOMOLOGS OF THE TWO SMALL GTPASES RAS1 AND RAS2 FROM THE HUMAN FUNGAL PATHOGEN PARACOCCIDIOIDES BRASILIENSIS

Fernandes, L. ${ }^{1}$; Andrade, R. V. ${ }^{2}$; Felipe, M. S. S. ${ }^{3}$

${ }^{1,2} \mathrm{UnB}$ - Department of Cell Biology; ${ }^{3} \mathrm{UnB}$ - Departament of Cell Biology

Introduction and objectives: Paracoccidioides brasiliensis is an ascomycete that displays a dimorphic temperature transition dependency, appearing as mycelium at $22{ }^{\circ} \mathrm{C}$ and at $37{ }^{\circ} \mathrm{C}$ as yeast, the virulent form. It is the causative agent of a systemic mycosis of high incidence in Latin America. Because of $P$. brasiliensis has the ability to infect and install in the host, there is an increasing need to elucidate the virulence mechanisms of this pathogen. The objective of this work is to characterize Ras 1 and Ras 2 homologs from P. brasiliensis for the fact that those genes codify for key regulators of signaling transduction pathways that regulate proliferation and differentiation in eukaryotes. Also, we have evaluated the expression of Ras1 and Ras2 transcripts during the dimorphic process of $P$. brasiliensis. Methods and Results: In the transcriptome analysis of P. brasiliensis - Pb01 (Yeast. 20: 263-71, 2003, J Biol Chem. 280: 24706-14) we found the PbAEST 983 corresponding to the Ras2 5' end, with an e-value $2 \mathrm{e}-11$ when compared to Aspergillus fumigatus RasB. We completely sequence the Ras 2 cDNA using primers T3 and T7 presented in the plasmid pBluescript where the PbAESTs were originally cloned. Ras2 (AY910576) displays an ORF of 716bp, an intron of 87bp and a putative protein of 238 aminoacids. As Ras1 was not presented by the transcriptome analysis of Pb01 isolate, we made a search in the Genbank, using the Ras1 gene sequence of Cryptococcus neoformans (AF294647) to BLAST against the deposited ESTs, and we found a sequence of $P$. brasiliensis (BQ493380) highly similar to the 3' end of Ras1. We designed primers based on this sequence and the PCR reaction was performed using genomic DNA from the isolate $\mathrm{Pb} 01$. The $602 \mathrm{bp}$ PCR product was sequenced and displayed a partial Ras1 sequence (DQ157363) with an intron of $99 \mathrm{bp}$. This fragment covers about $80 \%$ of the entire gene when compared to Ras 1 of other fungi. A multiple sequence alignment was performed to evaluate the similarities of the $P$. brasiliensis Ras GTPases among different fungi. We observed that Ras1 and Ras 2 are much conserved and are closely related to the A. fumigatus Ras A and RasB, respectively. To access the level of Ras 1 and Ras 2 transcripts in P. brasiliensis we performed a Northern blot experiment with specific probes during the dimorphic transition from mycelium to yeast. Ras1 and Ras2 do not have any difference in the level of transcripts appearing to be constitutively expressed during the mycelium to yeast transition. Conclusion: $P$. brasiliensis presents in its transcriptome both forms of Ras-GTPases, Ras1 and Ras2 that are conserved when compared to other Ras proteins from a variety of fungi. The constitutive expression observed during the dimorphic transition from mycelium to yeast in $P$. brasiliensis may be explained by the fact that those proteins present a high conservation of function in the control of the signaling pathways involved in proliferation and differentiation. Financial support: MCT/CNPq, CNPq, FAP-DF, FUB

\subsection{2 - THE PARACOCCIDIOIDES BRASILIENSIS ESTRADIOL BINDING PROTEIN HOMOLOG IS DIFFERENTIALLY EXPRESSED IN THE YEAST PHASE}

Nicola, A. M. ${ }^{1}$; Andrade, R. V. ${ }^{2}$; Felipe, M. S. S. ${ }^{3}$

${ }^{1,2,3} \mathrm{UnB}$ - Department of Cell Biology

Introduction and objectives: Paracoccidioides brasiliensis is a dimorphic and human pathogenic fungus, responsible for paracoccidioidomycosis (PCM), the most prevalent systemic mycosis in Latin America. The morphologic transition from mycelium to yeast, which can be reproduced in vitro, is essential for the establishment of fungal infection and can be blocked both in vivo and in vitro by the steroid hormone b-estradiol. This phenomenon has been postulated to be the cause of the early observed sexual bias in PCM, a disease which is found in an average of 20 men to one woman in spite of similar infection rates. In the early 1980 's a group isolated biochemically cytoplasmic steroid receptors in several fungi, including $P$. brasiliensis and Candida albicans. The same group cloned and sequenced the $C$. albicans receptor, naming it EBP1. We used this sequence to search in the P. brasiliensis transcriptome database and found a cDNA named PbEBP, which we are now initially characterizing. Methods: Database search was done with the tBLASTn tool. The sequence was analyzed using free online bioinformatics tools. Total mycelium and yeast RNAs were obtained by extraction with the TRIZOL reagent, separated by denaturing electrophoresis, blotted onto nylon membranes and hybridized with a radioactively labeled PbEBP probe. Results: The tBLASTn with the $C$. albicans EBP1 sequence resulted in an alignment with e-value of $10^{-56}$ with a $1434 \mathrm{bp}$ contig. The sequence presented an open reading frame encoding a putative protein with 395 aminoacid residues and predicted molecular weight of $43 \mathrm{kDa}$, which is very similar to $C$. albicans EBP1. The predicted protein sequence, when searche with BLASTp agains GenBank, aligns with several FMN-binding oxidoreductases from bacteria, plants and fungi, including $S$. cerevisiae Oye and $C$. albicans EBP1. Protein domain search using InterProScan (www.ebi.ac.uk/interpro) revealed a conserved NADH:flavin oxidoreductase motif. Prediction of its subcellular localization using PSORT II (psort.nibb.ac.jp) resulted in $69,6 \%$ chance of the protein being cytoplasmic. PbEBP has been shown to be differentially expressed in the yeast phase by electronic subtraction and microarray. We confirmed this expression pattern by Northern hybridization. Conclusion: The PbEBP cDNA encodes a protein which, after bioinformatics analyses, seems to be similar to the $C$. albicans estradiol binding protein. Although these results do not allow the conclusion that it is responsible for the physiological effects of estradiol in P. brasiliensis, we think that it is probably the longsought estradiol receptor. Additionally, we confirmed that the gene is differentially expressed in the yeast phase. Financial support: CNPq.
08.043 - THE STRESS RESPONSIVE AND MORPHOLOGICALLY REGULATED HSP90 GENE FROM PARACOCCIDIOIDES BRASILIENSIS IS ESSENTIAL TO CELL VIABILITY

Nicola, A. M. ${ }^{1}$; Andrade, R. V. ${ }^{2}$; Dantas, A. S. ${ }^{3}$; Albuquerque, P. ${ }^{4}$; Arraes, F. B. ${ }^{5}$; Silva Pereira, I. ${ }^{6} ;$ Felipe, M. S. S. ${ }^{7}$

1.2,3,4,5,6,7 UnB - Department of Cell Biology

Introduction and objectives: Paracoccidioides brasiliensis is a dimorphic and human pathogenic fungus, responsible for the most prevalent systemic mycosis in Latin America. The morphologic transition from mycelium to yeast can be reproduced in vitro by raising the cultivation temperature from room temperature $\left(\sim 25^{\circ} \mathrm{C}\right)$ to host temperature $\left(\sim 37^{\circ} \mathrm{C}\right)$; such increase in temperature causes a heat shock response with the induction of several hea shock proteins (HSPs), which help to fold denatured proteins and solubilize lethal aggregates. The response to heat shock, thus, is essential to the fungal pathogenesis. HSP90 is a molecular chaperone which aids in the folding of particular polypeptides and stabilizes their folded conformation. It has been shown to play important roles in the physiology and pathogenesis of other pathogenic fungi; therefore we decided to further study it. Methods: We obtained a phage bearing the full PbHSP90 cDNA from the transcriptome sequencing project. The clone was excised in vivo and fully sequenced with vector and internal primers. Southern blotting was used to determine the number of gene copies. Northern hybridizations were used to evaluate gene expression. Drug susceptibility microdilution tests were adapted from the international NCCLS standard M27-A2. Recombinant his-tagged HSP90 was produced using pET 21 a+ plasmid and Escherichia coli BL21 DE3 expression system. Results: The PbHSP90 cDNA sequence is identical to the one obtained by the transcriptome sequencing. Southern blotting demonstrated that, unlike mammals or some fungi the gene is encoded in a single copy in the genome, which means that this single gene must be constitutively expressed and stress regulated. We proved this by Northen hybidizations, which have shown that the gene is differentially expressed in the yeast phase, upregulated during the initial M to Y transition and by oxidative stress. The protein function was assessed by inhibition with geldanamycin and radicicol, which inhibited growth at 2 and $10 \mathrm{mM}$, respectively. Finally, we successfully produced recombinant his-tagged protein, which is currently in use to tes its role during fungal infection. Conclusion: Our results confirm that the PbHSP90 cDNA encodes a stress responsive protein whose function is essential to cell viability. Financial support: $\mathrm{CNPq}$

08.044 - PARACOCCIDIOIDES BRASILIENSIS ICL1 IN VITRO QUANTITATIVE GENE EXPRESSION ANALYSIS IN RESPONSE TO A NUTRICIONAL STRESS GROWTH CONDITION

Derengowski, L. S. ${ }^{1}$; Tavares, A. H. ${ }^{2}$; Silva Pereira, I. ${ }^{3}$

${ }_{1,2,3}$ Universidade de Brasília - Biologia Celular

Paracoccidioides brasiliensis, a facultative intracellular human pathogen, is the ethiologic agent of paracoccidioidomycosis (PCM), the most prevalent systemic mycosis in Latin America. It is assumed that this dimorphic fungus exists as a soil saprophyte, producing propagules that can infect humans and can cause the disease after the transition to the patogenic yeast form. The establishment of infection depends on the host immunological response and the fungal virulence. The most important mechanism of host defense against $P$. brasiliensis infection is the cell-mediated immune response, characterized by the production of cytokines In the absence of such cytokines, this fungus is able to survive and replicate within the phagossome of nonactivated murine and human macrophages. Thus, $P$. brasiliensis may have evolved mechanisms that made it able to survive within the phagocytic cells, considered a poor source of complex carbon. In agreement with its ability to survive in this inhospitable habitat, the analysis of $P$. brasiliensis transcriptome revealed several putative orthologues to virulence genes of other human facultative intracellular pathogenic fungi. In this sense, we identified orthologues of the glyoxylate cycle genes $i c l 1$ and $m l s 1$, encoding the regulatory enzymes isocitrate lyase and malate synthase, respectively. Due to the glyoxylate cycle importance in energy production-during infection, this pathway occurs in both virulent bacteria and fungi. In this context, the aim of this work was the semiquantitative analysis of glyoxylate cycle genes expression by RT-PCR technique. In order to evaluate the icl 1 and $m l s 1$ gene expression, the yeast form of $P$. brasiliensis was grown in media mimicking the phagossome millieu, in which glucose was replaced by acetate as a sole carbon source. Following different incubation times, cells were harvested and total RNA extracted. RT-PCR experiments were carried out using specific primers directed to the internal control gene ( $\alpha$-tubulin) and the experimental gene (icl 1 or $m l s 1)$. The RT-PCR produtcs were analysed by agarose ge electrophoresis and the amplified DNA fragments corresponding to $\alpha$-tubulin and one of the interest gene were quantified by densitometry employing the Scion Image software (http:// www.scioncorp.com). Our results suggest a slightly increase in the icl1 expression when this fungus was grown in media with acetate as the only carbon source. Financial support: FUNPE-DPP/UnB; FINATEC 
08.045 - GENE IDENTIFICATION DURING PARACOCCIDIOIDES BRASILIENSIS $(P B)$ CONIDIA TO YEAST TRANSITION

Garcia, A. M. ${ }^{1}$; Hernandez, O. ${ }^{2}$; Restrepo, A. ${ }^{3}$; Cano, L. E. ${ }^{4}$; Aristizabal, B. H. ${ }^{5}$; Marques, E. R. ${ }^{6}$; Sousa Bernardes, L. A. ${ }^{7}$; Goldman, G. ${ }^{8}$; Goldman, M. H. ${ }^{9}$; McEwen, J. G. ${ }^{10}$

${ }^{1,2}$ Corporación para Investigaciones Biológicas - Cellular and Immunogenetics Group; ${ }^{3.5}$ Corporación para Investigaciones Biológicas - Medical and Experimental Mycology Group ${ }^{4}$ Corporación para Investigaciones Biológicas - Medical and Experimental Mycology Group; ${ }^{6}$ Universidade de São Paulo - Ribeirão Preto - Laboratório de Biologia Molecular, Faculdade de Ciências ; ${ }^{7,8}$ Universidade de São Paulo - Ribeirão Preto - Laboratório de Biologia Molecula Faculdade de Ciências Farmacêuticas ; ${ }^{9}$ Faculdade de Filosofia Ciências e Letras de Ribeirão Preto - USP, SP - Departamento de Biologia; ${ }^{10}$ Corporación para Investigaciones Biológicas, Medellin, Colombia - Cellular and Immunogenetics Group

Introduction: The dimorphic fungus $P b$, is the causative agent of Paracoccidioidomycosis (PCM). The infection is probably acquired by inhalation of the infective mycelial propagules (conidia) produced at temperatures below $25^{\circ} \mathrm{C}$. When inhaled by the host they reach the alveolus and the host's temperature $\left(37^{\circ} \mathrm{C}\right)$ prompts their transition to the yeast form, the first step of the infectious process. This transition is pivotal for fungal survival and as such represents a suitable target to hinder initiation of the disease process. Objectives: Our purpose was to identify genes produced during the conidia to yeast transition by constructing an EST-Orestes library with further characterization of the corresponding sequences by automatic sequencing and identification by Blast analysis. Methodology: $\mathrm{Pb}$ strain ATCC 60855, was grown in its mycelial form in petri dishes with water agar medium for 3 months. Conidia were harvested by scraping the medium surface, purified by glasswool filtration, incubated at $37^{\circ} \mathrm{C}$ in $\mathrm{BHI}$ broth for 48 hours with shaking and the proportion of transitioned cells were counted microscopically. Total RNA was extracted using liquid nitrogen and Trizol ${ }^{\circledR}$ (Invitrogen). Total RNA was purified, amplified and cDNA produced with RiboAmp® (Arcturs) kit and used to perform PCR-Orestes as described by de Sousa et al 2000. Smears of the PCR-amplified cDNA were purified by elution from the agarose gel, selecting fragments between 500 to $2000 \mathrm{bp}$. The eluted fragments were cloned using TOPO TA cloning Kit $₫$ (Invitrogen), individual colonies were selected, plasmids were extracted from each colony and sequencing was made. Analysis and assembling of the EST-Orestes sequences was made using a pipeline built by the Molecular Biology group of the Faculty of Pharmaceutical Sciences, University of São Paulo, Ribeirão Preto, Brazil. Sequences were automatically edited for each EST-Orestes, cleaned from the vector using Phrap software and clustered using Cap3 softwares. Potential homologies with $P b$ genes were searched BlastX and BlasN algorithms against several databases. Results: 133 sequences were obtained that corresponded to 32 different sequences, 18 contigs and 14 singlets. Blast analyses with the different databases showed that $38 \%$ were unknown, $22 \%$ were hypothetical, $19 \%$ were from signal transduction, $9 \%$ corresponded to stress related proteins and 6 represent structura proteins. Eight $(25 \%)$ of the sequences had not been previously described in mycelial or yeast libraries, suggesting that they are specific for the conidial transition to yeast cells. Of these 8 sequences, 4 corresponded to unknown proteins, 3 to hypothetical proteins and one to a flavoprotein ubiquinone oxidoreductase (ETF-QO). Conclusions: Getting to know these genes is the firs step in understanding the host $-P b$ interactions as they should be involved in initiating the infectious process. Consequently, this information is pertinent for the development of strategies to hinder the first steps of the natural history of this fungal disorder Financial support: Colciencias: Project No. 22130412669, Contract 476-2002. CIDI - UPB CIB: Record 7918

\subsection{6 - IDENTIFICATION OF DIFFERENTIALLY EXPRESSED GENES IN PARACOCCIDIOIDES BRASILIENSIS MYCELIA AND YEAST FORMS USING A HIGH DENSITY GENOMIC DNA MICROARRAY}

Monteiro, J. P. ${ }^{1}$; Mirels, L. F. ${ }^{2}$; Clemons, K. V. ${ }^{3}$; Lopes, C. R. ${ }^{4}$; Stevens, D. A. ${ }^{6}$

${ }_{1,3,6}$ CIMR and Stanford University, CA, USA - Division of Infectious Diseases and Geographic Medicine ; ${ }^{2}$ CIMR and Santa Clara Valley Medical Center, San Jose, CA, USA - Division of Infectious Diseases; ${ }^{4}$ UNESP, Botucatu, SP, Brazil - Genetics Department

Introduction: Paracoccidioides brasiliensis is a dimorphic fungus in vitro and in vivo, and the etiologic agent of paracoccidioidomycosis. Mycelial (M) to yeast (Y) transition is a key step in initiation of infection. $\mathrm{M}$ and $\mathrm{Y}$ are also known to differ in nutritional requirements, cell wall composition, respiratory activity, membrane lipid composition and gene expression patterns. We report the construction of a random genomic DNA (gDNA) microarray containing some 12,300 elements and its initial application for detection of differentially expressed genes between $\mathrm{M}$ and Y. Methods: The P. brasiliensis microarray was assembled with amplified inserts (ca. 1 to $2 \mathrm{~kb}$ ) obtained from a Pb01 (ATCC\#MYA-826) random shear gDNA » ZAP II phage library. Inserts and known control genes were amplified by PCR, purified and printed onto glass slides. $\mathrm{M}$ and $\mathrm{Y}$ cells were harvested from 5-day-old cultures grown in modified McVeigh/Morton liquid (room temperature for $\mathrm{M}, 36^{\circ} \mathrm{C}$ for $\mathrm{Y}$, at 150 rpm). Cells were mechanically disrupted with zirconium beads and total RNA extracted using TRIzol. Cy5 labeled cDNA was synthesized using reverse transcription. Hybridizations were done in duplicate from each of two independent cultures using Cy5 labeled cDNA (sample) and Cy3 labeled gDNA (control) followed by in silico data extraction. Gene expression was normalized per spot to the gDNA channel, and per slide to known control genes. Clones showing e 3 -fold differences in expression (ANOVA $p<0.015$ ) when comparing M vs. Y were sequenced. Results: Excluding the controls, a total of 98 spots showed differential expression; 70 were more highly expressed by $\mathrm{Y}$ and 28 by M. Thus far, sequence analysis of 89 inserts indicates that 47 encode proteins with known function, 22 were similar to ESTs or proteins of unknown function and 20 had no identifiable homologue. In Y, highly expressed genes were related to respiration and mitochondrial function, protein metabolism, cell wall biogenesis, lipid metabolism, transcription, heat shock and iron uptake. Those expressed in higher amounts by $\mathrm{M}$ included genes related to protein degradation, RNA processing, salicylate hydroxylase, a thermotolerance related gene and two sugar transporters. Control genes upregulated in $\mathrm{M}$ were hydrophobin and $M 51$, and in $\mathrm{Y}$ were Y20, HSP104 and mannosyl transferase, confirming the reliability and specificity of the array. Conclusions: Our results confirmed previously known differences in gene expression between both forms and revealed additional candidate differentially expressed genes, adding further detail to the understanding of the biology of this organism. Financial support: Fogarty Training Grant (NIH/ERID)

\subsection{7 - ANALYSIS OF THE PBGP43 PROMOTER REGION OF PARACOCCIDIOIDES BRASILIENSIS BY DNASE I FOOTPRINTING AND ELECTROPHORETIC MOBILTY SHIFT ASSAYS \\ Rocha, A. A. ${ }^{1} ;$ Puccia, R. ${ }^{2}$}

${ }^{1,2}$ UNIFESP - MIP

Introduction and Objectives: Paracoccidioides brasiliensis is a dimorphic fungus known to cause paracoccidioidomycosis (PCM) in man. The gp43 of $P$ brasiliensis is the main diagnostic and prognostic antigen of PCM. It also elicits cellular immune response and protection against murine PCM in vaccinated mice. In addition, gp43 bears receptor(s) for murine laminin and may therefore be involved in adhesion and invasion of host cells. Gp43 is secreted in the culture supernatant of $P$. brasiliensis cultivated in vitro and can be detected as circulating antigen in the sera of infected individuals. In vitro, the yield of secretion varies with the isolate, growth phase and with regulating factors that are still unknown. We have provided the first evidences of transcriptional regulation of gp43, but we also observed that regulation at the protein and secretion levels may occur (Microbes Infect. 7:55-65, 2005) We also recorded differential gene regulation (down-regulation) upon heat shock in a funga sample $(\mathrm{Pb} 3)$ belonging to a phylogenetic group of isolates that have more substitutions in the promoter region than the others. Our laboratory is interested in understanding expression regulation of gp43. One approach to this problem is to investigate the control of PbGP43 gene expression by identifying transcription elements in the promoter region. Computer analysis of 306 base pairs of the known PbGP43 5' intergenic fragment identified many putative transcription elements. In a previous work, electrophoretic mobility shift assays (EMSA) using total extract of Pb339 identified at least one transcription element in the sequence tgcagatttatcaacaattatgca (BS8, -126 to -103) of the PbGP43 promoter region (Morais and Puccia, unpublished). Methods and Results: In the present work, DNAse I footprinting assays using the PbGP43 promoter fragment as probe and total extract of $\mathrm{Pb} 339$ revealed five protection regions between positions -261 and -146 (ET1 to ET5). EMSA was then performed to confirm the formation of binding complexes with oligonucleotides corresponding to the protected regions. We tested the probes ET1+2, ET2+3, ET4 and ET5 with total extracts of Pb339 and Pb3. We observed that ET4 and ET5 did not form binding complexes with either extract, but that the probes ET1+2 and ET2+3 formed strong binding complexes with both. The migration of the complexes varied with the extract, suggesting polymorphism in the transcription factors. Conclusions: The results presented here are promising and show that ET1, ET2 and ET3, besides BS8, are strong targets for the construction of truncated promoters to evaluate the function of these regions in the control of $\mathrm{PbGP} 43$ gene expression. Financial support: FAPESP and $\mathrm{CNPq}$

\subsection{8 - POSITIVE DIRECTIONAL SELECTION IN THE 43 KDA GLYCOPROTEIN GENE AMONG THE THREE PHYLOGENETIC SPECIES OF PARACOCCIDIOIDES BRASILIENSIS}

Matute, D. R. ${ }^{1}$; Rauscher, J. T. ${ }^{2}$; Puccia, R. ${ }^{3}$; Taylor, J. W. ${ }^{4}$; Restrepo, A. ${ }^{5}$; McEwen, J. G. ${ }^{1}$ Corporación para Investigaciones Bológicas - Biología Celular e Inmunogenética; ${ }^{2}$ University of Puerto Rico, Rio Piedras, Puerto Rico - Department of Biology; ${ }^{3}$ UNIFESP - MIP; ${ }^{4}$ University of California, Berkeley - Department of Plant and Microbial Biology; ${ }^{5}$ Corporación para Investigaciones Biológicas - Medical and Experimental Mycology Group; ${ }^{6}$ Corporación para Investigaciones Biológicas, Medellin, Colombia - Cellular and Immunogenetics Group

Introduction The neutral theory of evolution explains that the majority of changes at the molecular level are fixed by random drift of selectively equivalent mutations. Nevertheless, if a battle is established between the immune system of a host species and its pathogens, then selection will come to play a prominent role in the distribution of the molecular variation for genes involved in host-pathogen interactions. In this study, we evaluated the possibility of selection acting on the immunodominant antigen gp43 gene in $P$. brasiliensis, a recently described complex of closely-related phylogenetic species. We addressed the following questions: Is diversifying selection acting on gp43 in these species in order to avoid recognition by the host's immune system? Does the pathogenic life style lead to positive directional selection and increased rate of evolution in gp43 between the species? Likewise, two additiona analyses were performed to compare the information obtained in the selection analysis using a proteomic framework: i) the sequence of the gp43 was evaluated to establish the domain composition, and ii) a three-dimensional structure was developed using bioinformatics tools Methods and results To test for selection, we first amplified and sequenced the second exon of gp43, as well as partial sequences from the coding region of each of the two housekeeping 
genes glucane synthase and adenyl-rybosylation factor. The study was done in 65 individuals (fungal isolates) belonging to the three species. The true evolutionary history of the gp 43 gene is probably the same as the evolutionary history of the species because no conflictive sites were found. We used the aligned sequences from the coding regions of each locus to infer a phylogeny for the included species. Then we used these topologies as input for the likelihood analyses of positive selection. Given the results from the recombination tests (IST, Hudsons recombination parameter and g), as well as of the low observed intraspecific variability, we found linkage between collinear sites. We used likelihood-based methods to compare different types of selective pressure models among codons in order to analyze the mode of evolution of the genes. It was found that the gp43 gene evolves under positive selection, but the evaluated parts of the housekeeping genes evolved primarily by purifying selection. Conclusions We found a very low level of intraspecific variability and no evidence of diversifying selection, suggesting that the grater rate of evolution in the GP43 gene is not a result of evasion of the host's immune system. Financial support: This research was supported by grants from Fogarty International Research Collaboration Award (FIRCA) grant R03TW01308, Banco de la republica $N^{\circ} 1785$ and by funds of CIB and CODI, U de. Antioquia.

\subsection{9 - NUCLEOTIDE SEQUENCE DIVERSITY AT THE CHITIN SYNTHASE 2 LOCUS IN THE THREE PHYLOGENETIC SPECIES OF PARACOCCIDIOIDES BRASILIENSIS: AN EVALUATION OF THE BACKGROUND SELECTION}

Matute, D. R. ${ }^{\text {; }}$ Taylor, J. W. ${ }^{2}$; Restrepo, A. ${ }^{3}$; McEwen, J. G. ${ }^{4}$

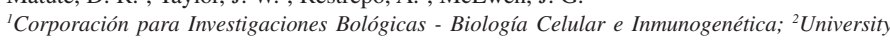
of California, Berkeley, California 94720 - 3Department of Plant and Microbial Biology; ${ }^{3}$ Corporación para Investigaciones Biológicas - Medical and Experimental Mycology Group; ${ }^{4}$ Corporación para Investigaciones Biológicas, Medellin, Colombia - Cellular and Immunogenetics Group

Introduction: The estimation of gene genealogies from DNA sequencing drawn from species or populations provides a powerful approach to quantify mutation, selection, genetic random drift, migration, and recombination. The current investigation was initiated to examine the causes of the polymorphism patterns found in the CHS2 gene in P. brasiliensis, and to determine if such variations patterns were caused by background selection. Methods and Results: The program SITES was used for polymorphism analysis and coalescent-based estimation of recombination rates where applicable. Tests of neutrality and determination of their associated significance were done by using the programs of Fu. The central result of this study related to the fact that $P$. brasiliensis data reject the null hypothesis of a pure drift mutation process based on all available statistical tests. When the data are partitioned into non-synonymous versus synonymous and intron sites, the departures from the null hypothesis are accounted for by an excess of singleton amino acid replacements. Conclusions: The distribution of synonymous and intron polymorphisms conform to neutral expectations. Recovery from a population bottleneck or a recent demographic expansion are both expected to lead to a transient excess of rare variants, but this would be true for all sites (synonymous and non-synonymous) and consequently, this explanation does not appear consistent with the observed data. Similarly, a selective sweep is not consistent with the distribution of synonymous and intron polymorphism because the recovery from a selective sweep would appear indistinguishable of recovery from a bottleneck for the region associated with a single locus. The most likely explanation for the accounted polymorphism distribution is the background selection hypothesis. Several features of the data appear to be consistent with this hypothesis. (i) There is no evidence for significant recombination within the P. brasiliensis CHS2 sequences. (ii) The amino acid replacements in the sample are all unique, as would be expected with weak negative selection. However, two additional features of the data need to be considered in concluding that selection against deleterious mutations is the primary determinant of the observed distribution of non-synonymous changes: $(i)$ there are nearly twice as many non-synonymous polymorphisms as synonymous polymorphisms in the sample (nine versus five); (ii) there appears to be no restriction on the type of amino acid change. These observations point to very weak negative selection on the amino acid replacements at non-synonymous sites. Financial support: This research was supported by grants from Fogarty International Research Collaboration Award (FIRCA) grant R03TW01308, Banco de la republica $\mathrm{N}^{\circ} 1785$ and by funds of CIB and CODI, U de. Antioquia.
08.050 - BIOINFORMATIC ANALYSIS OF PARACOCCIDIOIDES BRASILIENSIS 27 KDA ANTIGEN

Sepulveda, V. E. ${ }^{1}$; Matute, D. R. ${ }^{2}$; Restrepo, A. ${ }^{3}$; McEwen, J. G. ${ }^{4}$

${ }_{1,2}^{1.2}$ Corporación para Investigaciones Biológicas - Biología Celular e Inmunogenética; ${ }^{3}$ Corporación para Investigaciones Biológicas - Medical and Experimental Mycology Group; ${ }^{4}$ Corporación para Investigaciones Biológicas, Medellin, Colombia - Cellular and Immunogenetics Group

Introduction: Advancements in molecular biology have allowed production of reproducible and characterized antigenic proteins through cloning and sequencing. The cloning and sequencing of a $27-\mathrm{kDa}$ antigenic protein from P. brasiliensis (tr:P78725) opened the possibility for the use of this protein in clinical diagnosis. It is recognized by antibodies present in sera of Paracoccidioidomycosis (PCM) patients, and appeared to be free of crossreactivity. However, besides the sequence very few biological facts are known about this protein. Methods and results: We analyzed the characteristics of this protein using bioinformatics tools and the corresponding findings can be summarized as follows. First, sequence alignment studies and basic local alignment search tool (BLASTp) searches were performed. Based on the alignment it became apparent that although the protein has been found only in P. brasiliensis, some homologous sequences were also detected in Coccidioides immitis and Histoplasma capsulatum var. capsulatum. Moreover, a comparison against PROSITE indicates that the protein is weakly related to several previously reported profiles. Second, we deduced the secondary structure of the protein from sequence analysis using the programs JUFO and SCRATCH. It was not possible to deduce its three-dimensional structure, because not significant homology was found with a protein of known structure. Third, with the DNASP program, we determined its polymorphism among the protein belonging to the three phylogenetic species of $P$. brasiliensis recently described by our group, using several isolates from each one of such species. For this protein, the nucleotidic polymorphism was relatively low when compared with other antigenic proteins such as GP43. Fourth, the location of the protein was determined using the TMHMM program. The results indicate an extracellular location for this protein, either excreted, membranal or wall associated. No signal peptide has been associated to the protein. Finally, a search for potential epitopes was performed, finding several octamers, decamers and 15-mers, which might interact with the immune system. Conclusions: The low nucleotidic polymorphism might indicate that the gene encoding tr:P78725 is under selective constrain. Additional studies should be performed in order to confirm this hypothesis; nonetheless, we obtained new biologic information about the $27-\mathrm{kDa}$ antigen of $P$. brasiliensis complementing the protein's annotation. These types of tools may improve the knowledge in the evolutive biology in the antigenic proteins of $P$ brasiliensis. Financial support: This research was supported by a grant of Banco de la republica $\mathrm{N}^{\circ} 1785$ and by funds of CIB and CODI, U de. Antioquia.

\subsection{1 - MICROSATELLITE EVOLUTION IN PARACOCCIDIOIDES} BRASILIENSIS

Matute, D. R. ${ }^{1}$; Quesada, L. M. ${ }^{2}$; Sepulveda, V. E. ${ }^{3}$; Goldman, G. ${ }^{4}$ Taylor, J. W. ${ }^{5}$; Restrepo, A. ${ }^{6}$; McEwen, J. G. ${ }^{7}$

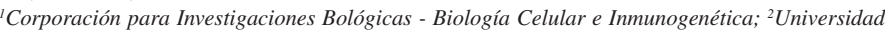
de Los Andes - Laboratorio de Micología Medica y Ambiental; ${ }^{3}$ Corporación para Investigaciones Biológicas - Biología Celular e Inmunogenética; ${ }^{4}$ Laboratório de Biologia Molecular, Faculdade de Ciências Farmacêuticas - Universidade de São Paulo - Ribeirão Preto; ${ }^{5}$ University of California, Berkeley, California 94720 - 3Department of Plant and Microbial Biology; ${ }^{6}$ Corporación para Investigaciones Biológicas - Medical and Experimental Mycology Group; ${ }^{7}$ Corporación para Investigaciones Biológicas, Medellin, Colombia - Cellular and Immunogenetics Group

Introduction: Microsatellite loci are important markers for population genetic analyses yet their evolutionary dynamics and mutational processes are still not fully understood with their role as phylogenetic markers being opened to discussion. In some microorganisms, such as $P$. brasiliensis, the existence of such markers has been demonstrated only recently. To address this issue, we sequenced eight microsatellites and their flanking regions in $65 P$. brasiliensis isolates obtained from several countries within the endemic area. Methods and results: To elucidate the genealogic relationships among alleles repeat number was mapped onto trees constructed from 18 nuclear regions. This allowed placement of the microsatellite mutations in the evolutionary context of the less rapidly evolving flanking regions and nuclear codifying genes. In a parallel way, it was possible to determine that the flanking regions evolve slower than the codying genes. This is consistent with expectations because the noncoding regions, such as the flanking regions, are more prone to accumulate mutations than the genes subjected to selective constrains. The distributions of the allele repeat number, within studied isolates and the phylogenetic species described by us, were consistent with the stepwise mutational model proposed for microsatellites. These results follow the same trend of information obtained in the case of Neurospora crassa. Conclusions: The flanking sequences were very similar among the three $P$. brasiliensis phylogenetic species analyzed. In a similar way, the allele repeat number distributions overlapped regularly because some alleles that were identical in state but not by descent, were shared among species. Additionally, several mutations in the tandem repeats themselves were observed within certain clades. The high levels of interspecific homoplasy (have the same phylogenetic origin) indicated that more microsatellite loci must be characterized before we can test their efficacy in phylogenetic reconstruction among $P$. brasiliensis phylogenetic species. Financial support: This research was supported by grants from Fogarty International Research Collaboration Award (FIRCA) grant R03TW01308, Banco de la República N¹785 and by funds of CIB and CODI, U de. Antioquia. 
08.052 - TRANSCRIPTOME ANALYSIS OF PARACOCCIDIOIDES BRASILIENSIS CELLS UNDERGOING THE MYCELIUM-TO-YEAST TRANSITION

Marques, E. R. ${ }^{1}$; Nunes, L. R. ${ }^{2}$; Oliveira, R. C. ${ }^{3}$; Leite, D. B. ${ }^{4}$; Silva, V. S. ${ }^{5}$; Ferreira, M. E. S. ${ }^{6}$ Ribeiro, D. C. D. ${ }^{7}$; Bernardes, L. A. S. ${ }^{8}$; Goldman, M. H. ${ }^{9}$; Puccia, R. ${ }^{10}$; Travassos, L. R. ${ }^{11}$ Batista, W. L. ${ }^{12}$; Nobrega, M. P. ${ }^{13}$; Nobrega, F. G. ${ }^{14}$; Yang, D. Y. ${ }^{15}$; Goldman, G..$^{16}$

${ }^{l}$ Faculdade de Ciências Farmacêuticas de Ribeirão Preto, USP. - Ciências Farmacêuticas, ${ }^{2,5}$ Universidade de Mogi das Cruzes - Núcleo Integrado de Biotecnologia; ${ }^{3,4}$ Universidade de Mogi das Cruzes - 1Núcleo Integrado de Biotecnologia; ${ }^{6}$ de Ciências Farmacêuticas de Ribeirão Preto, Universidade de São Paulo - Ciências Farmacêuticas; ${ }^{7}$ Universidade do Vale do Paraiba Laboratório de Biologia Molecular e Genomas; ${ }^{8}$ Faculdade de Ciências Farmacêuticas de Ribeirão Preto - Ciências Farmacêutica; ${ }^{9}$ Faculdade de Filosofia Ciências e Letras de Ribeirão Preto USP, SP - Departamento de Biologia; ${ }^{10}$ UNIFESP - MIP; ${ }^{11}$ UNIFESP - EPM - Microbiologia, Imunologia e Parasitologia; ${ }^{12}$ Universidade Federal de São Paulo - Microbiologia, Imunologia e Parasitologia; ${ }^{13}$ UNIVAP - Instituto de Pesquisa e Desenvolvimento; ${ }^{14}$ Univap - IP\&D; ${ }^{15}$ Tunghai University, Taichung, Taiwan - Department of Chemistry; ${ }^{16}$ Laboratório de Biologia Molecular, Faculdade de Ciências Farmacêuticas - Universidade de São Paulo - Ribeirão Preto

Paracoccidioides brasiliensis is a thermodimorphic fungus associated with paracoccidioidomycosis (PCM), a prevalent systemic mycosis in South America. In humans, infection starts by inhalation of fungal propagules, which reach the pulmonary epithelium and transform into the yeast parasitic form. Thus, the mycelial-to-yeast transition is of particular interest because conversion to yeast is essential for infection. We have used a $P$. brasiliensis biochip, carrying sequences of 4,692 genes from this fungus to monitor gene expression at several time points of the mycelium-to-yeast morphological shift (from 5 to $120 \mathrm{hs}$ ). Results revealed a total of 2,583 genes that displayed statistically significant modulation in at least one experimental time point. Among the identified genes, some encoded enzymes involved in amino acid catabolism, signal transduction, protein synthesis, cell wal metabolism, genome structure, oxidative stress response, growth control and development. The expression pattern of many genes was independently verified by real-time RT-PCR, revealing a high qualitative correlation $(\sim 85 \%)$ between the data obtained with the two methodologies. One gene, encoding 4-hydroxyl-phenyl pyruvate dioxygenase (4-HPPD) was highly overexpressed during the mycelium-to-yeast differentiation process and the use of NTBC, a specific inhibitor of 4-HPPD activity (as well as a series of NTBC derivatives) was able to inhibit growth and differentiation of the pathogenic yeast phase of the fungus in vitro. These data set the stage for further studies involving NTBC and its derivatives as new chemotherapeutic agents against PCM and confirm the potential of array-based approaches to identify new targets for the development of alternative treatments against pathogenic microorganisms. Financial support: FAPESP and CNPq

08.053 - CELL ORGANIZATION AND IONS TRANSPORTERS RELATED GENES ARE DIFFERENTIALLY EXPRESSED IN PARACOCCIDIOIDES BRASILIENSIS MYCELIUM AND YEAST CELLS

Andrade, R. V. ${ }^{1}$; Nicola, A. M. ${ }^{2}$; Carvalho, M. J. A. ${ }^{3}$; Fachin, A. L. ${ }^{4}$ Passos, G. A. S. ${ }^{5}$; Brigido, M. ${ }^{6}$; Felipe, M. S. S. ${ }^{7}$

1,2,3,6,7 Universidade de Brasília - UnB - Cell Biology; ${ }^{4,5}$ USP - Ribeirão Preto - SP - Genetic

Introduction and Objectives: The causative agent of Paracoccidioidomycosis (PCM), the thermo-regulated dimorphic fungus Paracoccidioides brasiliensis, is believed to be a free-living mycelium saprobe that undergoes transition to the yeast pathogenic form upon temperature change from the environmental $24-26^{\circ} \mathrm{C}$ to the mammalian body temperature of $37^{\circ} \mathrm{C}$. We had previously characterized 19,718 Expressed Sequence Tags (ESTs) from both mycelium and yeast cells [Felipe et al., J. Biol. Chem. 280(26), 24706-24714, 2005]. In this work, we have extended the analysis of $P$. brasiliensis transcriptome by assessing differentially expressed genes in mycelium and yeast cells by two different large-scale approaches: statistical analysis of gene expression based on EST counts (in silico ESTs subtraction) and cDNA microarrays. Methods: The 19,718 EST dataset were analyzed by in silico EST subtraction. From this set we have chosen 1,152 EST to further characterize by cDNA microarray analysis. The differential feature of selected genes was confirmed by Northern-blot assays. Results and conclusion: By comparing the results of both approaches, a sub-class of 83 clones was identified as differentially expressed genes. This final set of overlapped sequences was constituted by 19 and 64 up-regulated genes in mycelium and yeast cells, respectively. We have focus on the analysis of: (i) control of cell organization and (ii) ion metabolism and transporters related genes. Hex and BGL genes encoding for hexagonal peroxisome protein and 1,3 $\beta$-glucosidase, respectively, were identified as mycelium up regulated genes; while three other genes related to cell organization were shown to be up regulated in yeast cells, such as AGS ( $\alpha 1,3$-glucan synthase), CDA (chitin deacetylase) and VRP-verprolin. Genes involved in ion transporters, ISC and KTP, an iron-sulfur cluster and a potassium transporter respectively, were confirmed to be highly expressed in mycelium cells. Also, a putative P-type $\mathrm{Cu}^{+2}$ and choline sulfatase $(\mathrm{ChS})$ were up regulated in the yeast form. Therefore the data presented here contributes to further understanding the phase transition as a key feature for the life cycle of P. brasiliensis. Financial support: MCT, CNPq and FAPESP.

\subsection{4 - MOLECULAR STUDIES ON SULPHUR METABOLISM IN}

\section{PARACOCCIDIOIDES BRASILIENSIS}

Ferreira, M. E. S. ${ }^{1}$; Marques, E. R. ${ }^{2}$; Savoldi, M. ${ }^{3}$; Restrepo, A. ${ }^{4}$; Nunes, L. R. ${ }^{5}$; Oliveira, R. C. ${ }^{6}$; Goldman, M. H. ${ }^{7}$; Goldman, G. ${ }^{8}$

$1,2,3,8$ FCFRP - USP - Ciências Farmacêuticas; ${ }^{4}$ Corporation para Investigaciones Biologicas Medelin, Colombia; ${ }^{5,6}$ UMC - Núcleo Integrado de Biotecnologia; ${ }^{7}$ FFCLRP - USP - Ciências Farmacêuticas

Introduction and Objectives: The dimorphic pathogenic fungus $P$. brasiliensis is a cysteine prototrophic in the mycelial (non-pathogenic) form, but cysteine auxotrophic in the yeast (pathogenic) form. The main objective of this study is to verify the molecular basis of this phenomenon. As a preliminary step to understand the organic sulfur auxotrophy in $P$. brasiliensis yeast form, we decided to characterize the positive regulator MetR and the sulfur metabolite repression SconC homologues in this fungus. Methods and Results: We have grown 79 P. brasiliensis strains from different environments and geographical locations in minimal medium supplemented either with inorganic or organic sulfur. None of these strains was able to grow in minimal medium in the absence of organic sulfur, indicating that organic sulfur auxotrophy is a broad phenomenon in this species. Furthermore, P. brasiliensis is not able to grow in anaerobiosis and the organic sulfur auxotrophy is not related to high $\mathrm{O} 2$ tension. We evaluated the mRNA and protein expression during the dimorphic transition and demonstrated these genes are able to complement the corresponding A. nidulans metR and sconC3 mutants. In addition, to perform a more complete description of the genes that are transcriptionally induced during the hyphal-to-yeast transition in minimal medium supplemented with organic sulfur as single sulfur source (MM+CCM), we accomplished a large-scale analysis of gene expression in $P$. brasiliensis by using microarray hybridizations. Conclusion: Our results showed that both P. brasiliensis METR and SCONC genes were able to complement the $A$. nidulans mutants. In addition, several genes previously seen as more expressed during the transition in complete YPD medium are also more expressed in $\mathrm{MM}+\mathrm{CCM}$, suggesting these genes are important for the transition independently of the culture conditions. Financial support: FAPESP and CNPq, Brazil. 